\title{
Propuesta de Jardín Botánico Integral para La Conservación del Ecosistema de Humedales
}

\author{
Diana Belén Gutiérrez Vallejo \\ María Daniela Hidalgo Molina
}

Artículo

Afiliación: Universidad Espíritu Santo-Ecuador, Facultad de Arquitectura, Guayas, Ecuador

E-mail: dbgutierrez@uees.edu.ec

mdhidalgo@uees.edu.ec

Recibido: 29 de enero del 2019

Aceptado: 27 de mayo del 2019

\section{Diana Belén Gutiérrez Vallejo}

Arquitecta, autora del trabajo de titulación

"Propuesta de Jardín Botánico Integral para La Conservación del Ecosistema de Humedales", proyecto que fue adaptado como artículo académico, Universidad Espíritu Santo-Ecuador Facultad de Arquitectura

María Daniela Hidalgo Molina

Arquitecta, PhD. Profesora Investigadora,

Universidad Espíritu Santo-Ecuador, Facultad de Arquitectura.

\begin{abstract}
Resumen
La presente investigación toma como protagonista a la parroquia satelital La Puntilla, en el cantón de Samborondón de la provincia de Guayas y se dispone a estudiar antecedentes pertinentes al caso tales como su origen y crecimiento urbano. Asimismo, este pretende tomar el modelo de desarrollo al cual ha estado sujeto junto con los antecedentes antes mencionados, los cuales desembocan en la identificación de problemas palpables dentro de la realidad urbana y ambiental de la ciudad que afectan de forma crítica su calidad de vida y futuro social. Mediante la investigación de teorías para el entendimiento de la figura de estudio que abarca desde la sostenibilidad de las ciudades hasta la conceptualización de uno de los ecosistemas predominantes en Samborondón (ecosistema de humedales), se logra profundizar aún más en la hipótesis a plantear. Esto, con la ayuda de herramientas metodológicas anexas a la participación ciudadana tales como encuestas y entrevistas. Finalmente, los resultados metodológicos y el análisis de sitio respectivo son recursos claves para la materialización de la propuesta de modelo de jardín botánico para la parroquia satelital La Puntilla. Esto bajo el concepto de ecotono urbano que procura conservar el ecosistema de humedales presente en terreno de uso agrícola, potenciando así la sinergia entre la comunidad y su naturaleza circundante.
\end{abstract}

Palabras clave: conservación de humedales; desarrollo urbano sostenible; ecotono; espacios urbanos-rurales; jardín botánico

Wetlands' conservation through a botanical garden as a transitional space between the urban and the rural

\begin{abstract}
The following investigation has an analytical-synthetic character and takes as main figure the emergent city of Samborondón. It studies the background information pertinent to the case such as its origin and urban growth. It also examines the model of development to which it has been subject, which ends in the identification of tangible problems within the urban and environmental reality of the city, critically affecting its quality of life and social future. Through the investigation of valid theories for the understanding of the figure of study that ranges from urban sustainability to the conceptualization of one of the most significant ecosystems in Samborondón (the wetland ecosystem), it is possible to expand more in the hypothesis presented. Moreover, the analysis of the theories goes hand in hand with attached methodological tools requiring citizen participation such as surveys and interviews. Finally, the methodological results, the study of analogous cases, and the respective site analysis are key resources for the materialization of the proposed botanical garden model for La Puntilla. These seek to conserve the wetland ecosystem present in agricultural land under the concept of urban ecotone, enhancing the synergy between the community and its surrounding nature.
\end{abstract}

Keywords: Botanical Garden; ecotone; Sustainable urban development; urban-rural spaces; wetland conservation 
Tabla 1.Información general.

Fuente: Gobierno Autónomo descentralizado, 2014.

\section{Introducción}

$\mathrm{D}$

eacuerdo con las Naciones Unidas, se prevé para el 2030 que alrededor de 5000 millones de personas habiten en las urbes. El 95\% de la expansión de los terrenos urbanos en las próximas décadas tendrá lugar en el mundo en desarrollo (Naciones Unidas, 2015). Por tanto, es necesario implementar las políticas tratadas en la Agenda 2030 y los 17 objetivos del Desarrollo Sostenible en los planes de desarrollo de las ciudades, tanto en el contexto urbano como rural. De llevarse a cabo de forma eficiente estas políticas, se reforzaría las relaciones entre las zonas urbanas y rurales, contribuyendo así a la construcción de sistemas económicos, sociales y medio ambientales más estables y fuertes.

\section{Tabla 1}

Información general

\section{Datos Generales}

\begin{tabular}{l|l} 
Nombre: & $\begin{array}{l}\text { Gobierno Municipal Autónomo Descentralizado del Cantón } \\
\text { Samborondón }\end{array}$ \\
Creación del cantó & Octubre 31, 1995 \\
Población & 85075 (Proyección, GAD 2014). \\
Extensión & $389,05 \mathrm{~km}^{2}$
\end{tabular}

Dentro del marco de las ciudades emergentes, es plausible exponer como caso puntual al cantón Samborondón de la provincia del Guayas en Ecuador (Ver figura 1 y tabla 1). Hace más de 100 años, el espacio geográfico que en la actualidad conforma a Samborondón formaba parte del cantón Guayaquil al haber estado anexado a la jurisdicción de este, alcanzando su cantonización en el año de 1955. Este contaba con una población de 5000 habitantes con tan sólo 495 viviendas (Gobernación del Guayas, 2018). El proceso de urbanización y dotación de infraestructura urbana correspondiente a servicios básicos data desde 1932, año en el cual se ubicó la primera planta eléctrica del cantón. Para el año de 1976, se instaló el primer tendido eléctrico para Samborondón, el cual suministraba el servicio de electricidad desde Guayaquil, mientras que los primeros trabajos correspondientes a suministro de agua potable y alcantarillado fueron realizados para el año de 1969 (Alcaldía de Samborondón, 2018).

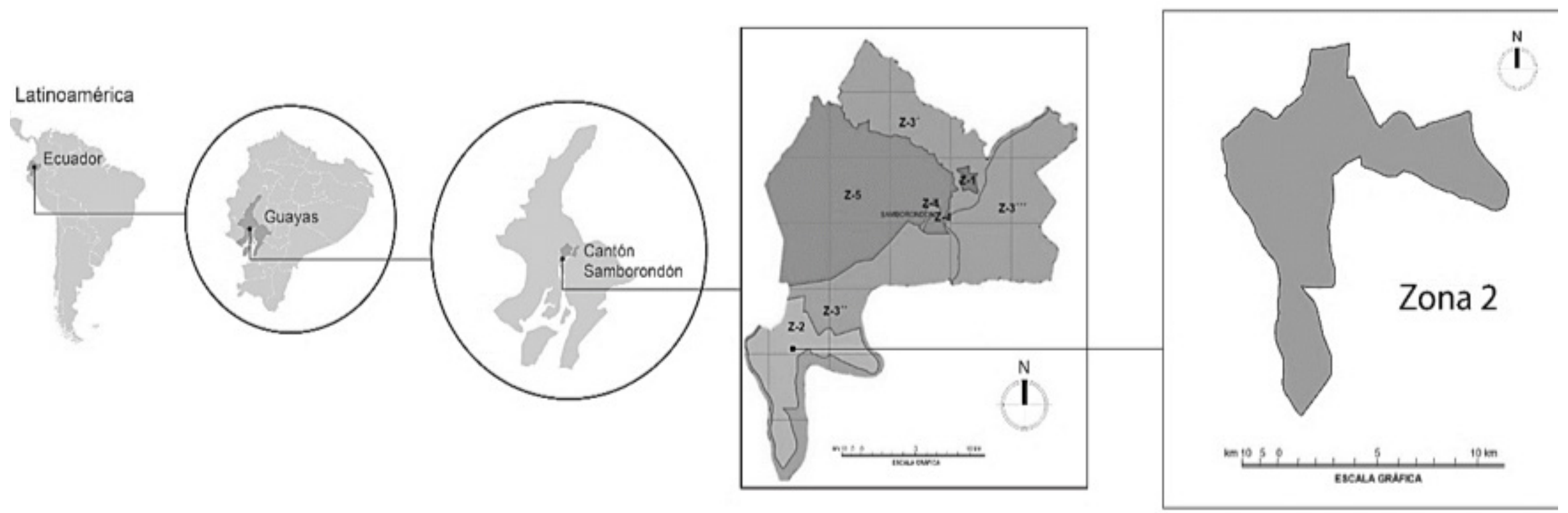

Figura 1. Ubicación del cantón Samborondón Parroquia Urbana La Puntilla

Fuente: Mapa del Plan de Desarrollo de

Ordenamiento Territorial PDOT, adaptadp por Carla Orozco, 2018
El cantón Samborondón corresponde a la Zona 8, junto con Durán y Guayaquil, según las agendas zonales establecidas por la Secretaría Nacional de Planificación y Desarrollo. Se divide en dos zonas y cabecera cantonal: la zona urbana conformada por la parroquia urbana satélite La Puntilla y la zona rural compuesta por la extensión de territorio que abarca pequeños poblados y recintos de las parroquias Tarifa y Boca de Caña, además de la cabecera cantonal Samborondón (Supraquam, 2015). 
$1 \quad$ Las Agendas Zonales se adaptan a las zonas administrativas de planificación del país en provincias y cantones. En total la Secretaría Nacional de Planificación y Desarrollo, planificó 9 zonas en todo el territorio del Ecuador. La Zona 8, corresponde a los cantones de Guayaquil, Samborondón y Durán. (Secretaría Nacional de Planificación y Desarrollo, 2015).
El cantón ha conservado las actividades agrícolas, principalmente la producción de arroz, representando así una fuente de trabajo substancial sobre todo para el segmento rural del cantón. Cabe destacar que el sector rural cuenta con más de cien asentamientos rurales disgregados en la extensión de su territorio, los cuales a pesar del acelerado desarrollo de la zona urbana siguen enfrentando dificultades en cuanto a conectividad y servicios básicos en la actualidad (Secretaría Nacional de Planificación y Desarrollo, 2015).

El crecimiento urbano del cantón de Samborondón inicia a partir de la construcción de dos infraestructuras viales: el puente de la Unidad Nacional y la Vía Perimetral. Originalmente, el puente de la Unidad Nacional, inaugurado en el año de 1970, impulsó las actividades económicas del cantón, contribuyendo así al inicio de nuevas actividades comerciales. Posteriormente, la conexión vial entre las extensas áreas de terrenos baldíos o de uso agrícola fue posible con la habilitación de la Vía Perimetral en el año de 1987, contribuyendo así al cambio y diversificación del uso de suelo en el cantón y haciendo posible la ejecución de proyectos urbanísticos (Gobierno Autónomo Descentralizado de la Municipalidad de Samborondón, 2015).

Actualmente, el cantón presenta una serie de problemáticas que engloban asuntos de inequidad social y económica, marcadas por la coexistencia de modernos proyectos habitacionales privados de crecimiento horizontal junto a extensos territorios rurales que mantienen necesidades básicas hasta el día de hoy insatisfechas. Además, existen serias deficiencias medio ambientales sin atender. Es con base a toda la compleja red de sistemas por considerar y planificar que ciudades emergentes como Samborondón merecen medidas inmediatas con alcance de un desarrollo sostenible.

Específicamente para la región Latinoamericana, la complejidad de sus transformaciones urbanas resultó ser la base para que, espacios geográficos que se mostraban como pequeños pueblos agrícolas, pasaran a convertirse en ciudades intermediarias, acarreando de tal forma una serie aspectos por resolver, que, en el presente, representan todas aquellas problemáticas que las máximas autoridades de los gobiernos locales deben enfrentar. Es en base a este nuevo esquema urbano que surge una serie de oportunidades y amenazas para las ciudades intermediarias, también denominadas "ciudades emergentes".

Con base a lo establecido por la Agenda Zonal ${ }^{1}$ para la Zona 8, existen diversas necesidades que mantienen una estrecha relación con el ámbito socio-espacial determinado por los espacios verdes urbanos, derivados del diagnóstico ambiental integral del sector. Problemáticas tales como contaminación y deforestación de ecosistemas por actividades productivas, impacto ambiental por el crecimiento insostenible de los principales centros urbanos, débil intervención ciudadana en la conservación del patrimonio natural y vulnerabilidad ante amenazas naturales y antrópicas (Secretaría Nacional de Planificación y Desarrollo, 2015) son varios de los asuntos más importantes de ser atendidos con urgencia para así forjar un futuro sostenible para el cantón.

Es por esto por lo que, como objetivo general, el proyecto busca proponer un Jardín Botánico Integral para la Parroquia Samborondón, bajo el concepto de Ecotono Urbano, que conserve el ecosistema de humedales existente en un terreno de uso agrícola. Gracias a la asesoría de la doctora Natalia Molina, en cuanto al enfoque del tema de conservación de humedales en el sector. Para llegar a este objetivo, se llevó a cabo una investigación primaria por medio de encuestas y entrevistas, documentación secundaria, análisis de sitio, análisis de casos análogos, que no se muestran en el artículo pero sí en el trabjo de titulación (Gutiérrez Vallejo \& Hidalgo, 2019). Por último, se realizó también el anteproyecto con esquema funcional, cuadro de necesidades, concepto de diseño, criterios y la planimetría respectiva.

\section{Problema/Justificación}

Las ciudades del mundo ocupan solo el $3 \%$ de la tierra, pero representan entre el $60 \%$ y el $80 \%$ del consumo de energía y el $75 \%$ de las emisiones de carbono. Pese a ser mínima la ocupación de las ciudades comparado con el territorio global, el consumo de 
energía y emisiones de carbono con alto porcentaje de afectación deriva en una serie de problemas ambientales que afectan la calidad de vida de los habitantes. Durante las últimas décadas, las sociedades han enfocado sus esfuerzos en alcanzar un equilibrio entre los asentamientos humanos y los espacios naturales. Por ejemplo, los Objetivos de Desarrollo Sostenible (ODS), también conocidos como Objetivos Mundiales por las Naciones Unidas, buscan mejorar las condiciones de las ciudades del mundo (Naciones Unidas, 2015).

En el cantón Samborondón, el territorio presenta una superficie total de 38913,90 Ha. de las cuales la cobertura vegetal natural es apenas de $2419,28 \mathrm{Ha}$., lo que deriva en un porcentaje insuficiente de áreas verdes o reforestadas $(6,22 \%)$ en relación al área total del cantón (Gobierno Autónomo Descentralizado Municipal del Cantón Samborondón, 2012). Además, según información demográfica, la población es de 85.075 habitantes (GAD, 2014) y se proyecta que el cantón Samborondón acogerá una población total urbana de 101,402 habitantes para el año 2022 (INEC, 2010). La parroquia urbana carece de espacios de esparcimiento, recreación, conservación de biodiversidad, bosques protectores, áreas de recreación e interpretación ambiental, corredores verdes y fluviales de importancia turística (Supraquam, 2015); por lo tanto, al tomar en cuenta la proyección de aumento de población, es necesario establecer políticas urgentes de desarrollo sostenible.

La configuración territorial de la Parroquia La Puntilla es la de un embudo con una vía principal denominada Avenida Samborondón de $10 \mathrm{~km}$ de longitud. Siendo esta la única vía, se conecta directamente con las vías terciarias de las urbanizaciones cerradas. Además, a partir de un análisis observacional del mapa satelital, se evidencia la existencia de aproximadamente 180 proyectos habitacionales o urbanizaciones residenciales dentro del área que abarca la parroquia La Puntilla (ARCGIS, 2018), predominando el uso residencial de densidad baja. Eso incrementa el uso vehicular para acceder a otros equipamientos, siendo una de las razones del embotellamiento vehicular que los ciudadanos viven a diario.

Una realidad que enfrenta Samborondón en la actualidad resulta en la necesidad de diversificación de usos de suelo, como por ejemplo el incrementar los usos recreativos. Dentro de las actividades económicas del cantón, el comercio al por mayor y menor representa el $31,75 \%$ del total de actividades frente al $1,37 \%$ que figura de las actividades relacionadas al entretenimiento y recreación (Gobierno Autónomo Descentralizado Municipal del Cantón Samborondón, 2012). Adicionalmente, se ha registrado un déficit de actividades ecoturísticas que establezcan una relación naturaleza-usuario dentro de la zona urbana del cantón, siendo los únicos espacios turísticos existentes en la actualidad los siguientes: Parque Histórico, Teatro Sánchez Aguilar, Santuario de Schoenstatt, Museo de presidentes, Hipódromo Miguel Salem Dibo, Antiguo Palacio Municipal, Plaza Cívica Carlos López Jiménez, Ruta de Alfareros, paseos en canoa, astilleros artesanales, peleas de gallos, centro turístico y deportivo Río Vinces, parques acuáticos, cabalgatas y festivales gastronómicos (Supraquam, 2015).

La falta de espacios comunes o públicos que atiendan las necesidades de la población en cuanto a recreación y ocio presenta un porcentaje del 1,37\% correspondiente a actividades relacionadas con el entretenimiento dentro del cantón; además, el déficit de áreas verdes naturales dentro de su contexto urbano-rural cuenta con tan solo el $6,22 \%$ correspondiente a áreas verdes en relación al área total del cantón (Gobierno Autónomo Descentralizado Municipal del Cantón Samborondón, 2012). Tomando en cuenta lo anterior, resulta urgente y necesario la provisión de espacios urbanos verdes que establezcan conexiones óptimas entre el contexto urbano y nativo de la zona, fortaleciendo así el uso de suelo destinado a la recreación, esparcimiento y entretenimiento de los habitantes en donde también se rescata el panorama ecológico del cantón. 


\section{Marco teórico: espacios de transición entre lo urbano y rural}

La ciudad, al mostrarse como un sistema abierto y dinámico que se encuentra en constante transformación como respuesta a diversas influencias, presenta a los espacios urbanos públicos como componentes estructurantes determinados por la diversidad de los territorios desde un marco socioespacial, dentro del cual estos promueven una calidad de vida óptima, equitativa y sostenible. Ciudades emergentes como Samborondón, con el crecimiento y proceso de evolución urbana que ha presentado durante la última década, demanda la integración de espacios públicos dentro de su trama urbana como parte de la búsqueda de una constitución urbana sustentable.

Por lo que se refiere al desarrollo sostenible de la sociedad a nivel mundial, la gestación de dicho término radica en los años 1980, tiempo durante el cual existió un gran debate internacional y una necesidad de llevar a cabo discusiones y procesos de cambio que tuvieran como objetivo principal dar solución a todas aquellas problemáticas sociales, económicas y medio ambientales que los países más desarrollados estaban enfrentando (Estenssoro, 2014). El debate internacional, determinado por la toma de conciencia e incompatibilidades resultantes de crecimientos demográficos, económicos y tecnológicos hasta cierto punto desmesurados, tuvo como resultado la publicación del Informe Brundtland, también denominado Nuestro Futuro Común, presentado en el año de 1987 por la Comisión de Desarrollo y Medio Ambiente dirigida por la entonces primer Ministro de Noruega, Gró Harlem Brundtland (López, 2015).

Fue entonces cuando finalmente se introdujo a la sociedad el concepto de desarrollo sostenible que se definió en los siguientes términos: "Está en manos de la humanidad asegurar que el desarrollo sea sostenible, es decir, asegurar que satisfaga las necesidades del presente sin comprometer la capacidad de las futuras generaciones para satisfacer las propias" (Gómez, 2014). Ciertamente, la concepción de este nuevo término generó gran interés en varias ramas del conocimiento y en lo que corresponde de manera específica al campo del urbanismo. El desarrollo sostenible influye de forma directa en los procesos de diseño y edificación (Hernández, 2008).

El origen y convivencia de centralidades y periferias dentro de las ciudades representa un asunto determinante que capta los distintos criterios y morfologías de organización social (Torres, 2013). En este caso, el espacio urbano podría determinarse como aquella "centralidad", mientras que el espacio rural, inevitablemente dentro del contexto latinoamericano, representa muchas veces los remanentes de territorio 0 escenarios periféricos donde el desarrollo social, económico y político aún no han sido forjados.

Es posible definir al espacio urbano como aquella área urbanizada y conformada por edificaciones e infraestructuras que presentan una complejidad considerable en cuanto a su composición, ya que no posee usos de suelo agrícola y mantiene una continuidad física respecto a un núcleo. Sin embargo, este sí suele tener presencia de formas territoriales ajenas a lo urbano tales como bosques, cuerpos de agua o campos agrícolas a manera de interrupciones en el espacio (Ávila, 2009). Por otro lado, la raíz del concepto de espacio rural hace alusión a aquellas áreas periféricas abiertas, y externas al desarrollo físico de la ciudad, que por lo general cuentan con la presencia y predominio de actividades de producción agrícola (Cuesta, 2012).

Más allá de las diferencias que puedan existir al momento de establecer las definiciones respectivas para cada concepto, lo esencial de esta categorización territorial que presentan las ciudades se encuentra en la búsqueda de un nuevo espacio de cohesión urbano-rural que se constituya como un espacio autónomo. Asimismo, que este presente condiciones de vida exclusivas al estar regulado por sus diversos componentes y cuente además con la intervención de agentes externos que contribuyan a la formación de sistemas de organización con capacidad de congruencia y transición (Neu, 2016).

Por lo tanto, en la búsqueda de aquella área emergente que logre cohesionar estos dos espacios de naturalezas opuestas -urbano y rural- y moldeando desde el ámbito físico-espacial el contexto natural 0 artificial para consolidar así las sociedades que han sido fragmentadas a distintos niveles, aparece una configuración espacial a manera de área transitoria, es decir, un área de expansión urbana o punto de convergencia de formas de vida diversas y escenarios cambiantes (Kayser, 1972). Es este paisaje intermedio dentro del cual se determinará una escala donde sea posible evidenciar la 
manera en la cual ocurra una interacción de variables sociales, naturales y humanas, lo que se denomina como Ecotono Urbano.

Como parte de los desarrollos urbanos, la existencia de espacios de transición se da a manera de sectores que, dentro de las ciudades, alivian aquella transformación brusca entre las tipologías territoriales que las conforman. Básicamente, estos espacios de transición no son más que áreas dentro de las cuales la interacción de dos estructuras divergentes se resuelve y sus heterogeneidades se diluyen (Cuesta, 2012). En esencia, estos paisajes intermedios funcionan a manera de vínculo, generando una canalización y un nexo entre dos zonas que naturalmente no se reconocen mutuamente. Es así como nace el concepto del Ecotono Urbano.

El Ecotono Urbano es un término que encuentra su origen alrededor de los años 1950, aludiendo a aquellas zonas intermedias o transitorias entre dos ecosistemas al margen de los grandes biomas. En la actualidad, este concepto trata de espacios, tiempos y energías en vinculación con medios abiertos desde el enfoque urbano (Neu, 2016). El presente concepto puede ser considerado en la práctica como una estrategia que se define como área transitoria entre el contexto natural y urbano con el fin de alcanzar distintos modos de integración y vínculos, en donde los actores principales son el espacio y el habitante (Alfonso Olaya \& Riascos Romo, 2016).

Además, es posible establecer que esta estrategia urbana presenta cambios 0 variaciones de diversas condiciones vitales, relacionadas con aspectos básicos del medio biofísico, que se puede interpretar como una competencia de los componentes de los biomas contiguos, en la cual los medios y distintas formaciones de cada uno de los ecosistemas involucrados se individualizan (Neu 2016). Adicionalmente a esta premisa, se establece que la estructuración del tejido de un ecotono urbano, debe estar vinculada con la idea de alternatividad de desarrollo, la cual, con sus metodologías auto organizativas, define la autorregulación de las distintas formas urbanas (Cuesta 2012).

En lo que respecta a los objetivos planteados para la aplicación de esta estrategia urbana transitoria, los mismos abarcan diversas dimensiones. Dentro de la dimensión urbana, el ecotono busca la integración de tejidos urbanos densos, para así alcanzar una alta productividad social, cultural y urbana (Kayser, 1972). Correspondiente a la dimensión ecológica, el ecotono urbano procura el alcance de una regulación de la acción antrópica a la cual se enfrentan de forma constante los distintos ecosistemas que forman parte de los asentamientos humanos, así como la recuperación de la conectividad ecológica (Alfonso Olaya \& Riascos Romo, 2016).

Los ecotonos urbanos representan en definitiva una estrategia de transformación, ya que incentiva un tejido de interacciones sociales locales que se relaciona con los demás tejidos interactivos del medio urbano. En este sentido, la integración de la interacción social se considera como herramienta principal de acción al espacio público (Cuesta, 2012). La implementación de esta estrategia urbana servirá como área transitoria integradora de las diversas dinámicas sociales. La forma en la que se percibe al medio natural pasará de la delimitación y cuidado de las zonas naturales como componentes aislados a la integración de estas como áreas destacadas y representativas que presentarán valores funcionales y culturales como parte del modelo de planeación de la ciudad (López, 2014).

\section{Metodología}

El proceso metodológico del proyecto utiliza herramientas mixtas cualitativas y cuantitativas. La herramienta cuantitativa correspondiente a encuestas busca medir estadísticamente el fenómeno de estudio a partir de aspectos determinantes, partiendo de las varias percepciones provenientes de la población de estudio. De tal forma, se conceptualiza la realidad actual con base a la información recolectada de la población seleccionada.

Para el cálculo de la muestra de estudio para población finita con un error del $10 \%$ y nivel de confianza de 95\%, se consideró el universal de 100,000 habitantes correspondientes al cantón de Samborondón, que resultó en una muestra de 96 pobladores a encuestar (ver Tabla 2). 
Tabla 2. Cálculo de Muestra Poblacional Fuente: Elaboración propia
En cuanto a la herramienta cualitativa, esta se aplica para profundizar en el fenómeno de estudio y evitar caer en la generalización de la información. Más allá de medir, mediante el presente método se cualifica y describe a partir de aspectos determinantes la temática, contexto y dimensiones que abarca la investigación según las distintas percepciones de los actores dentro de la población de estudio. Por medio del método cualitativo se pretende comprender la situación o asunto investigativo de forma integral, teniendo en consideración sus características y dinámica. La herramienta por aplicar dentro del método cualitativo para la presente investigación corresponde a entrevistas.

\section{Tabla 2.}

\section{Cálculo de Muestra Poblacional}

\begin{tabular}{c|c} 
Proporción & 0,5 \\
\hline Error Muestral & $10 \%$ \\
Nivel de Confianza & $95 \%$ \\
Nivel de Significancia & $5 \%$ \\
$\mathbf{Z}$ & 1,96 \\
$\mathbf{N}$ & 100000
\end{tabular}

Tamaño de muestra

96

\section{Resultados de la investigación}

Correspondiendo al enfoque cualitativo de la metodología aplicada, se realizaron entrevistas a cuatro profesionales pertenecientes a instituciones públicas y fundaciones relacionadas con la temática que engloba el presente tema de investigación. Se contó con la participación del Lcdo. Fernando García Alarcón, Director de Ordenamiento Territorial, y de la Lcda. Allys Luey, Directora de Turismo, ambos pertenecientes al Gobierno Autónomo Descentralizado de Samborondón. Además, representando a la Fundación La Iguana se contó con la colaboración de la Srta. Andrea Fiallos y el Sr. Francisco Martínez. Esta fundación lleva a cabo campañas y eventos con fines medioambientales tal como lo es la reforestación urbana.

Gran parte de las dificultades que enfrenta el cantón se deben a que este territorio no fue concebido como una nueva ciudad desde un principio. En lugar de esto, se le proyectó como una especie de ciudad dormitorio para Guayaquil. Es por este motivo que, con el crecimiento exponencial que enfrenta en la actualidad, los aspectos relacionados al desarrollo urbano sostenible tales como implementación de espacios verdes públicos, arborización de vías de circulación e integración del peatón a la ciudad mediante aceras amplias y ciclovías son esenciales para elevar la calidad de vida urbana. Esto procura que la naturaleza sea integrada a la zona urbana, incentivando un sistema de movilidad urbana sustentable y promoviendo un verdadero sentido de comunidad entre los habitantes de la zona con el objetivo que finalmente se evite el crecimiento aislado que ha caracterizado al cantón hasta el día de hoy.

En cuanto a ocio y recreación, las autoridades municipales han tenido como principal enfoque turístico al sector rural, sobre todo al que corresponde al territorio que conforma la Cabecera Cantonal con el fin de destacar todos aquellos íconos, atributos y tradiciones culturales y sociales del cantón. De hecho, la facilidad turística de mayor acogida es la Plaza Cívica Carlos López Jiménez, ubicada en la cabecera cantonal. Sin embargo, es posible establecer que varias de las deficiencias urbanas presentes en Samborondón se deben a que se ha dado prioridad solo al turismo rural de la cabecera, mientras que en la zona correspondiente a la parroquia urbana La Puntilla, las actividades de mayor acogida son aquellas que resultan de las inversiones privadas, resultando en un turismo gastronómico y comercial.

A pesar de que ciertamente gran parte de la comunidad urbana de Samborondón disfruta de este enfoque recreacional y de esparcimiento presente en la zona urbana, este no contempla espacios verdes públicos debido a la inexistencia de los mismos. Si se pone en consideración los aspectos que verdaderamente determinan la calidad de vida óptima de una ciudad, será evidente que las deficiencias dentro de Samborondón 
Figura 2 Edad de la Población de Estudio. Fuente: Elaboración propia (2018).

Figura 3 Género de la Población de Estudio. Fuente: Elaboración propia (2018).

Figura 4 Ubicación del Domicilio en Ciudadelas Privadas.

Fuente: Elaboración propia (2018). que se encuentran dentro de un solo espacio urbano delimitado, que cuentan con un acceso 0 entrada principal restringido para el cuidado de la seguridad de los habitantes, que usualmente constan de equipamientos recreativos de uso común y exclusivo para los habitantes de la ciudadela. son alarmantes y que la brecha social es grande, presenciando así una real paradoja en la cual se tiene el metro cuadrado más caro del país con las condiciones de vida de los sectores más pobres en lo que a urbanismo respecta.

En definitiva, Samborondón necesita convertirse en una verdadera ciudad mediante la implementación de reformas legales y proyectos que fomenten el crecimiento sostenible y el mejoramiento de la calidad de vida de su ciudadanía. Es importante el compromiso de todos los habitantes y autoridades para la consolidación de las metas que se planteen en pro de la ciudad. Más substancial aún es disminuir el poder que ejercen los promotores urbanísticos sobre el modelo territorial que se establezca para el cantón. Resulta incoherente la existencia de un territorio inmobiliario tan "lujoso" que no cuente siquiera con los elementos más básicos que hacen de una ciudad un espacio digno para vivir, como lo son los espacios públicos.

\section{Encuestas}

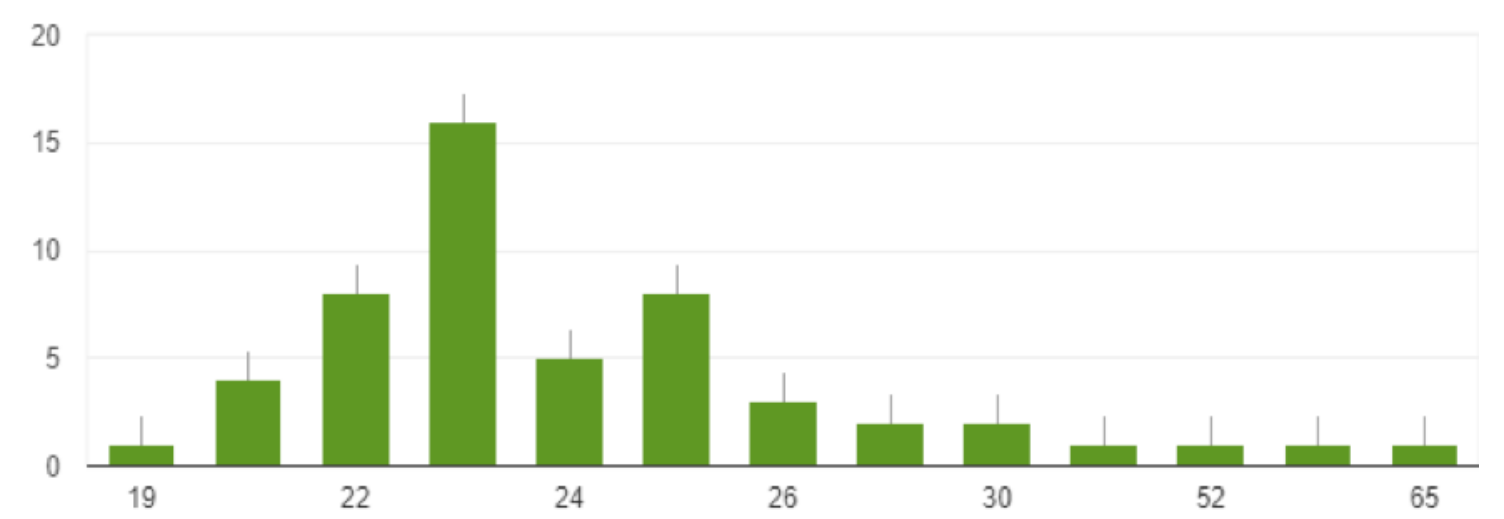

Como parte de la metodología y proceso de recolección de datos asignados para el proyecto, se diseñó un cuestionario adjunto en el anexo con el propósito de obtener información cuantitativa que de razón y soporte al problema planteado contemplando los fenómenos tanto sociales como urbanos identificados. A continuación, se muestran los resultados obtenidos de las encuestas realizadas a la muestra poblacional de estudio.

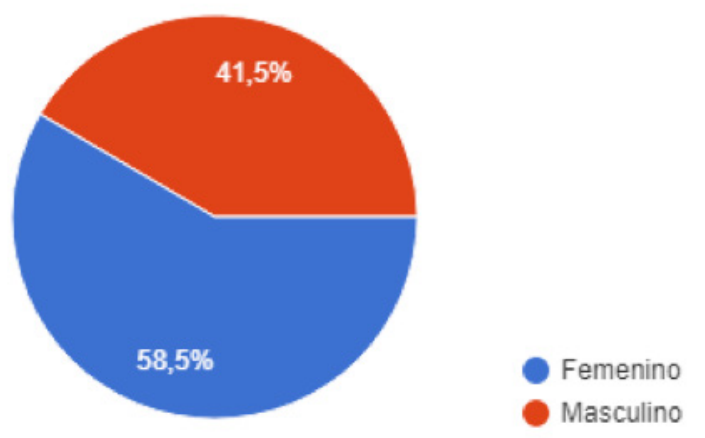

Se muestra la concentración de edades de la muestra poblacional mediante la Figura 2. Los habitantes con la edad de 23 años presentaron mayor participación en la encuesta con un $30,20 \%$. Por otra parte, se encuentra la participación de los habitantes con edades de 22 y 25 años, quienes comparten el mismo porcentaje de participación correspondiente al $15,10 \%$ respectivamente. Con un menor grado de participación, se muestra la población con edades en el rango de 19 a 22 años de edad, así como de 26 a 65 años de edad.

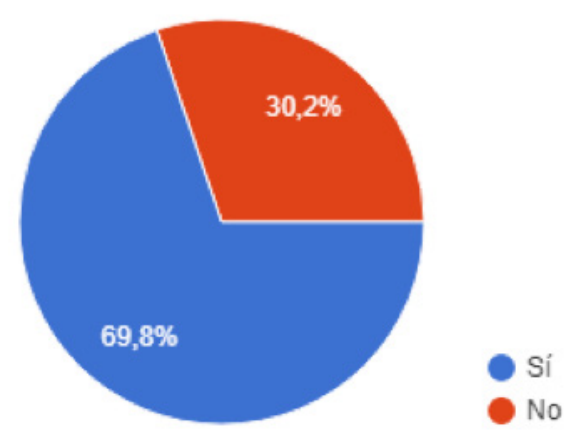

Se contó con una participación predominante de habitantes de género femenino, mismo que en la Figura 2 muestra un porcentaje correspondiente al 58,50\%; por otro lado, el género masculino cuenta con un porcentaje de participación menor que corresponde al $41,50 \%$ restante de la población de estudio. 
Figura 5. Existencia de deficiencias medioambientales en Samborondón Fuente: Elaboración propia (2018).
Figura 6. Deficiencias medioambientales dentro de Samborondón.

Fuente: Elaboración propia (2018).
Figura 7. Preferencia de zonas para la Propuesta de Jardín Botánico. Fuente: Elaboración propia (2018)

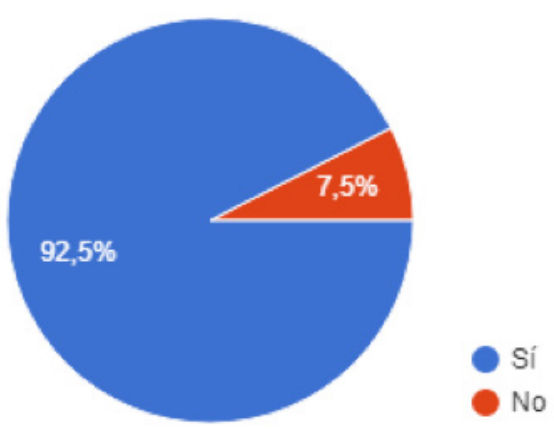

A partir del cuestionario realizado, se logró identificar la localización del domicilio de la población encuestada, logrando cuantificar de tal forma la procedencia de los distintos puntos de vista a mostrar en el desarrollo de la encuesta y así obtener un porcentaje mayoritario del $69,80 \%$ que corresponde a ciudadanos que efectivamente residen dentro de una ciudadela privada de Samborondón. El restante $30,20 \%$ corresponde a los participantes que no residen dentro de una ciudadela privada ${ }^{2}$ del cantón, registro reflejado en la Figura 4.

En lo que respecta a la percepción de la existencia de deficiencias medioambientales dentro de la gestión municipal de Samborondón, se encuentra la Figura 5, que con un porcentaje predominante del $92,50 \%$ deja en evidencia la afirmación por parte de la población de que efectivamente existen deficiencias medioambientales. Con un porcentaje mínimo correspondiente al 7,50\%, la población restante niega que existan estas mencionadas deficiencias.

\section{Falta de espacio verdes públicos amplios.}

No existen reservas o zonas naturales protegidas.

Excesiva contaminación atmosférica y auditiva.

Falta de follaje vegetal en la vía pública.

Destrucción masiva de ecosistemas naturales.

Deficiencia de proyectos y campañas de

concientización ambiental.

No considero que existan deficiencias ambientales.

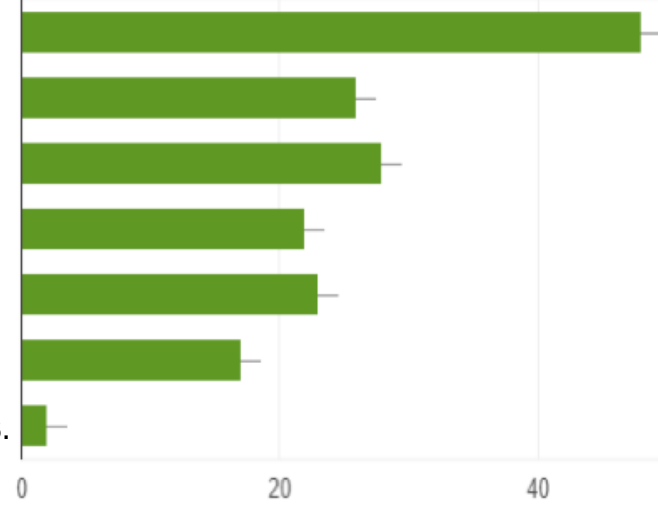

60

En función de la interrogante planteada previamente, mediante la Figura 6 se observan específicamente cuales son dichas deficiencias existentes dentro de Samborondón según la perspectiva de la población encuestada. Como aspecto predominante, la mayor parte de la población considera que la falta de espacios verdes públicos amplios es la carencia medioambiental más crítica que presenta el cantón con un $28,92 \%$ del total de las respuestas registradas. Como segunda deficiencia predominante, se encuentra la excesiva contaminación atmosférica y auditiva a raíz de los distintos medios de transporte que recorren la ciudad, contando con un 16,87\%. Finalmente, la población de estudio considera como tercera deficiencia medio ambiental más preocupante dentro de Samborondón la inexistencia de reservas o zonas naturales protegidas, mostrando un porcentaje del $15,66 \%$.
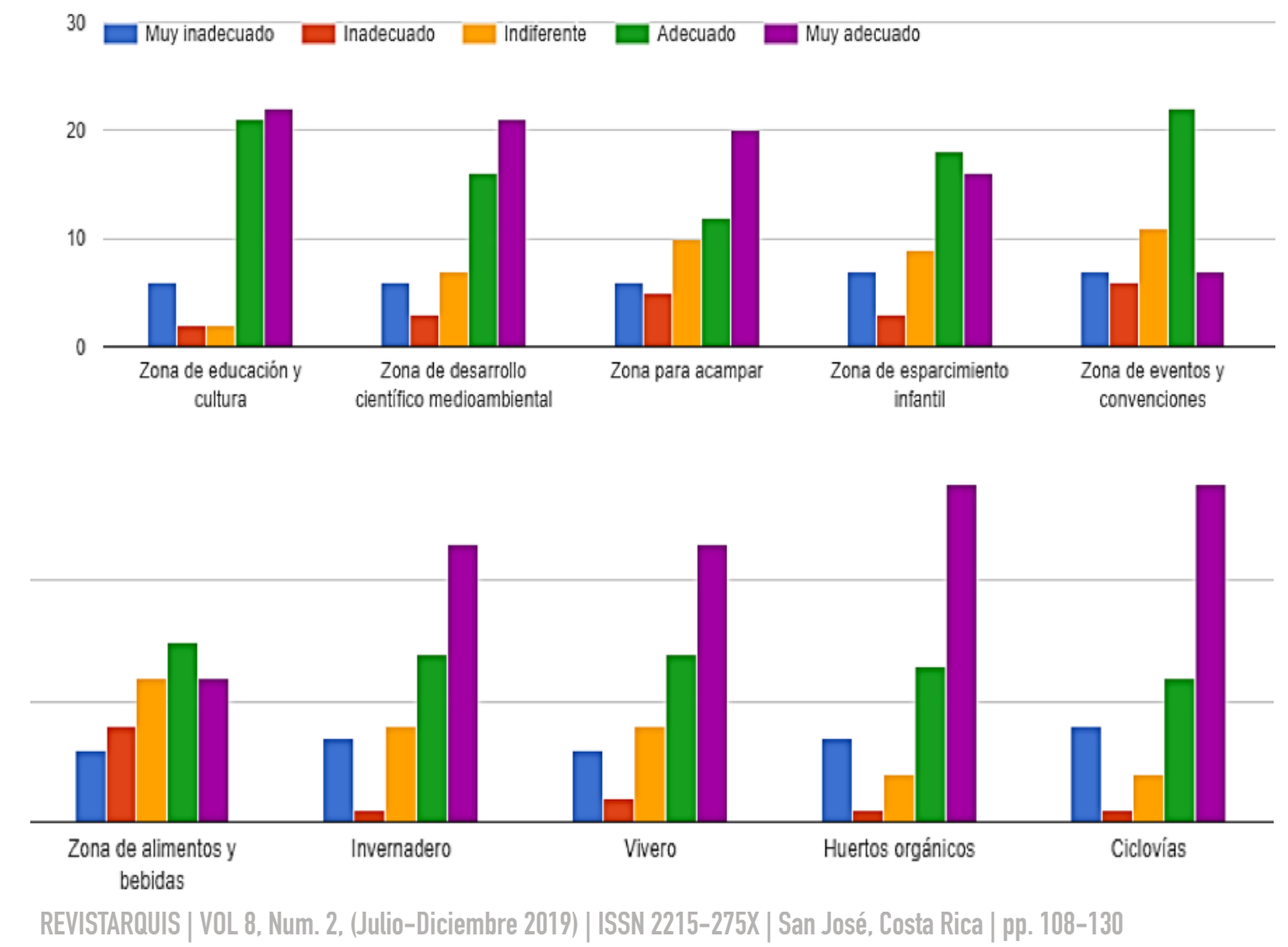
Figura 8. Ubicación de Zona Urbana de Estudio. Y Fuente: Municipio de Guayaquil, adaptado por autor (2018).
Como parte final de la encuesta planteada a la muestra poblacional de estudio, se pidió que califiquen en un rango cualitativo de muy inadecuado a muy adecuado una serie de 10 zonas a considerar como parte de la propuesta de Jardín Botánico, calificaciones reflejadas en la Figura 7. Los participantes mostraron un interés mayoritario para las zonas destinadas a huertos orgánicos, ciclovías, vivero e invernadero, las cuales muestran un predominio en la calificación correspondiente a muy adecuado. Asimismo, con rangos de calificación de adecuado a muy adecuado, se encuentran las zonas destinadas a educación y cultura, desarrollo científico medioambiental y esparcimiento infantil. Se pone en evidencia que, al parecer de la ciudadanía encuestada, una zona destinada a alimentos y bebidas no se percibe como muy adecuada para el proyecto propuesto.

Análisis de Sitio
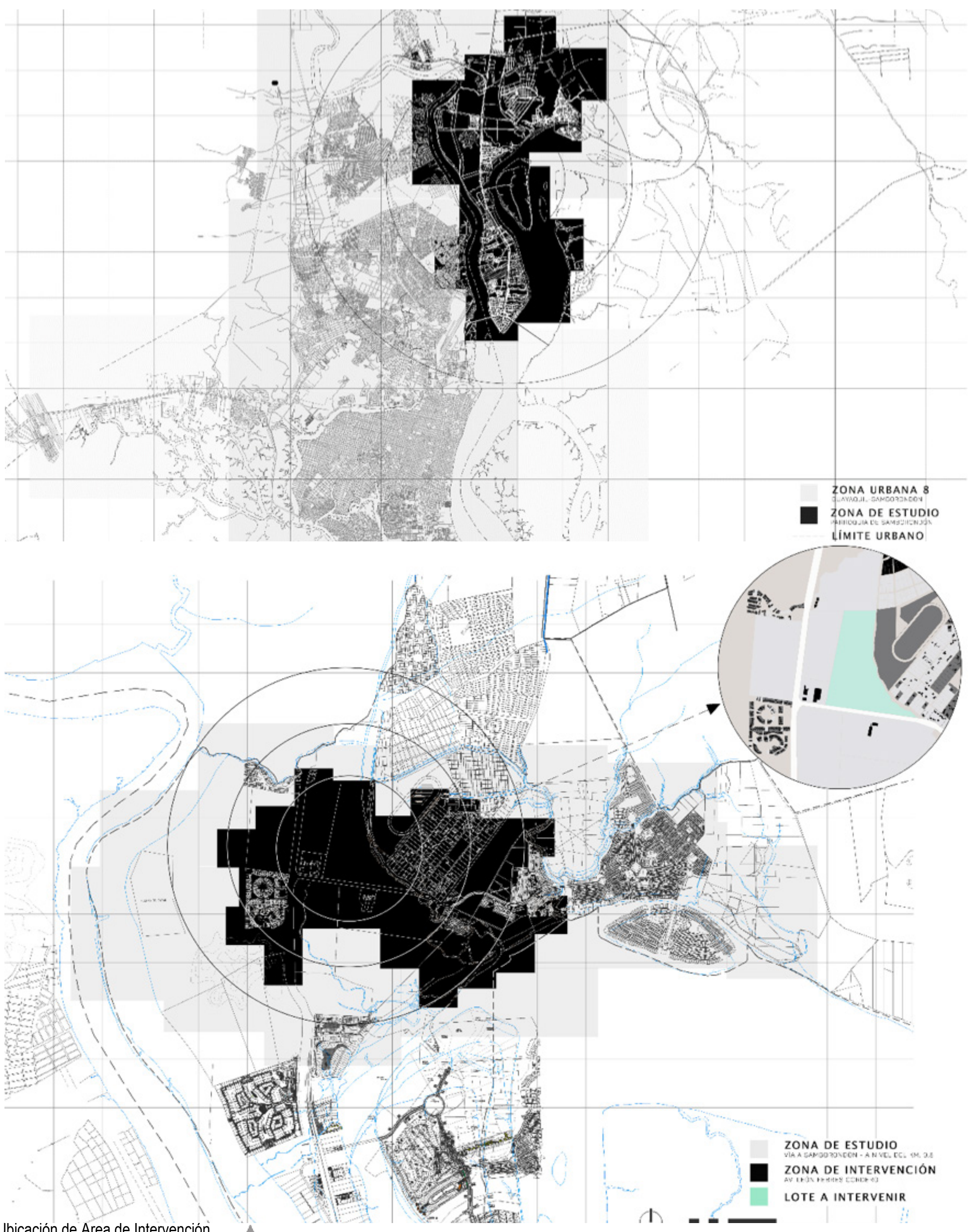
Usos de suelo:

Como punto de partida para el análisis de sitio, se analizaron los distintos usos de suelo del sector a intervenir, mismo que según el mapa de Zonificación Territorial de Samborondón pertenece a la zona censal Z2, que implica el territorio perteneciente a la parroquia Satélite La Puntilla(GobiernoAutónomo Descentralizado dela Municipalidad de Samborondón, 2015). El análisis fue realizado con base a las clasificaciones estándares de usos de suelo Land Based Classification Standards (LBCS) correspondientes a la categoría de actividades (ver Figura 10).

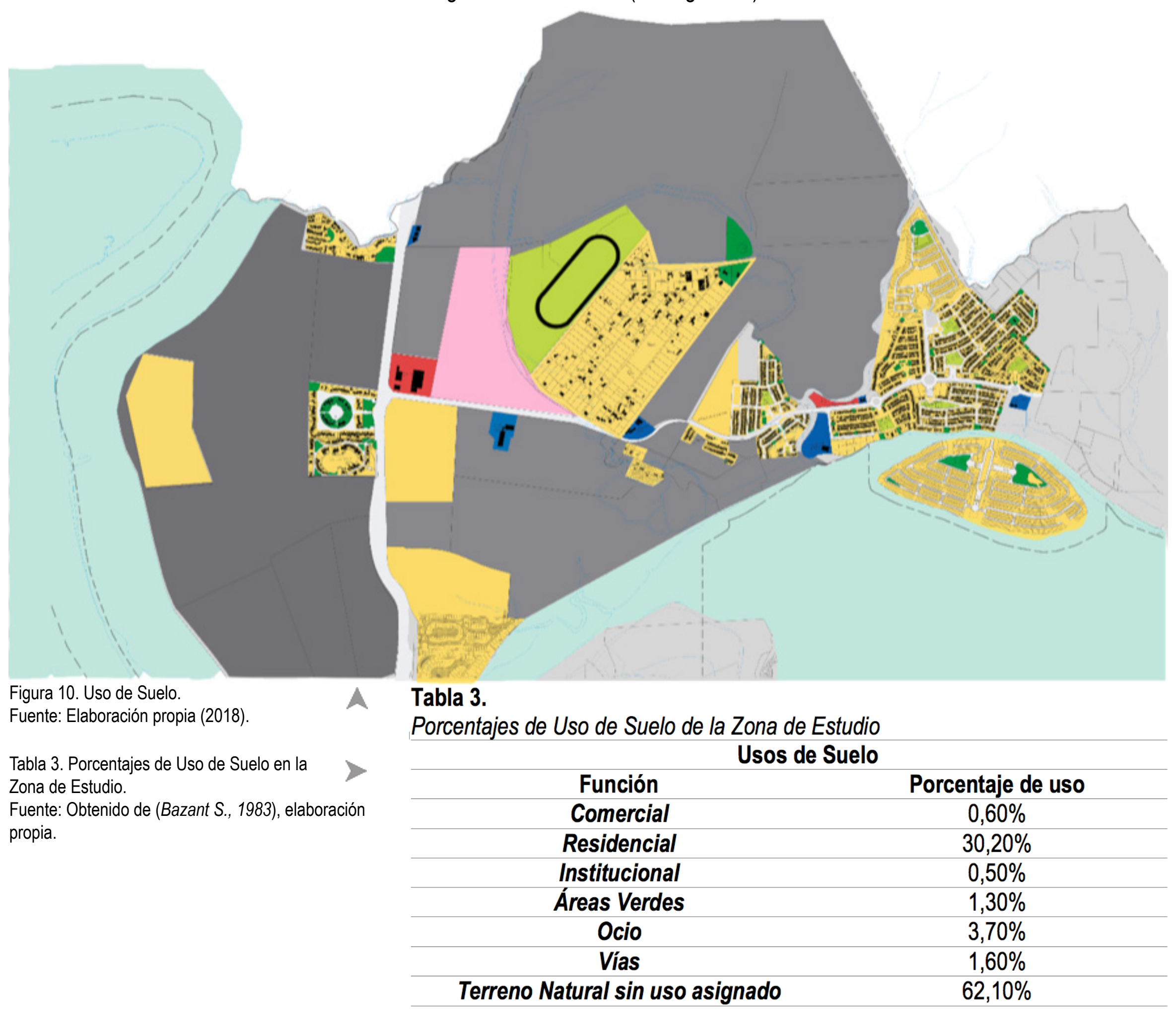

La Tabla 3 muestra que dentro de la zona a intervenir existe un desequilibrio notorio entre los distintos usos de suelo presentes, dado que el porcentaje correspondiente al uso de suelo residencial $(30,20 \%)$ supera con gran diferencia a los demás usos de suelo señalados en el mapa. Además, el uso de suelo correspondiente a áreas verdes $(1,30 \%)$ resulta ser crítico en función del área total de los distintos espacios a los cuales debe servir dentro de la zona de intervención. Dichos espacios considerados como áreas verdes no resultan de uso público, ya que sirven exclusivamente a los usuarios que residen dentro de las distintas urbanizaciones privadas de la zona. Se establece entonces que existe una deficiencia crítica de uso de suelo destinado a áreas verdes dentro del área de estudio. 
Tabla 4. Normas y Coeficientes de Uso de Equipamiento.

Fuente: Obtenido de (Bazant S., 1983), elaboración propia.

Figura 11. Radios de Uso de Equipamiento Fuente: Elaboración propia (2018).
Radios de uso de equipamientos:

En función de las Normas y Coeficientes de Uso de Equipamiento establecidos por los criterios de diseño urbano del autor Jan Bazant (1983), se generará el análisis del radio de influencia o radio de uso que abarcan los distintos equipamientos que forman parte del sector a intervenir para el proyecto (ver Figura 11). A continuación, se detallan los equipamientos identificados que componen la estructura urbana del sitio de estudio, junto al radio de uso respectivo (ver Tabla 4).

Tabla 4.

Normas y Coeficientes de Uso de Equipamiento

\begin{tabular}{ccc}
\hline & Equipamientos & Radios de Uso (m) \\
\hline \multirow{2}{*}{ Educación } & Jardín de niños & 500 \\
& Primaria & $500-1000$ \\
& Secundaria & $1000-2000$ \\
\hline \multirow{3}{*}{ Administración } & Ayuntamiento & Ciudad \\
& Bomberos & Ciudad \\
& Planta potabilizadora & Ciudad \\
& Planta de tratamiento de aguas & Ciudad \\
Comercial & negras Subestación Eléctrica & Ciudad \\
& Grandes tiendas & Ciudad \\
& Supermercado & $500-1000$ \\
\hline \multirow{2}{*}{ Recreación/Cultural } & Templos & Barrio \\
& Centro Deportivo & Barrio \\
& Áreas Verdes & $500-1000$ \\
\hline
\end{tabular}

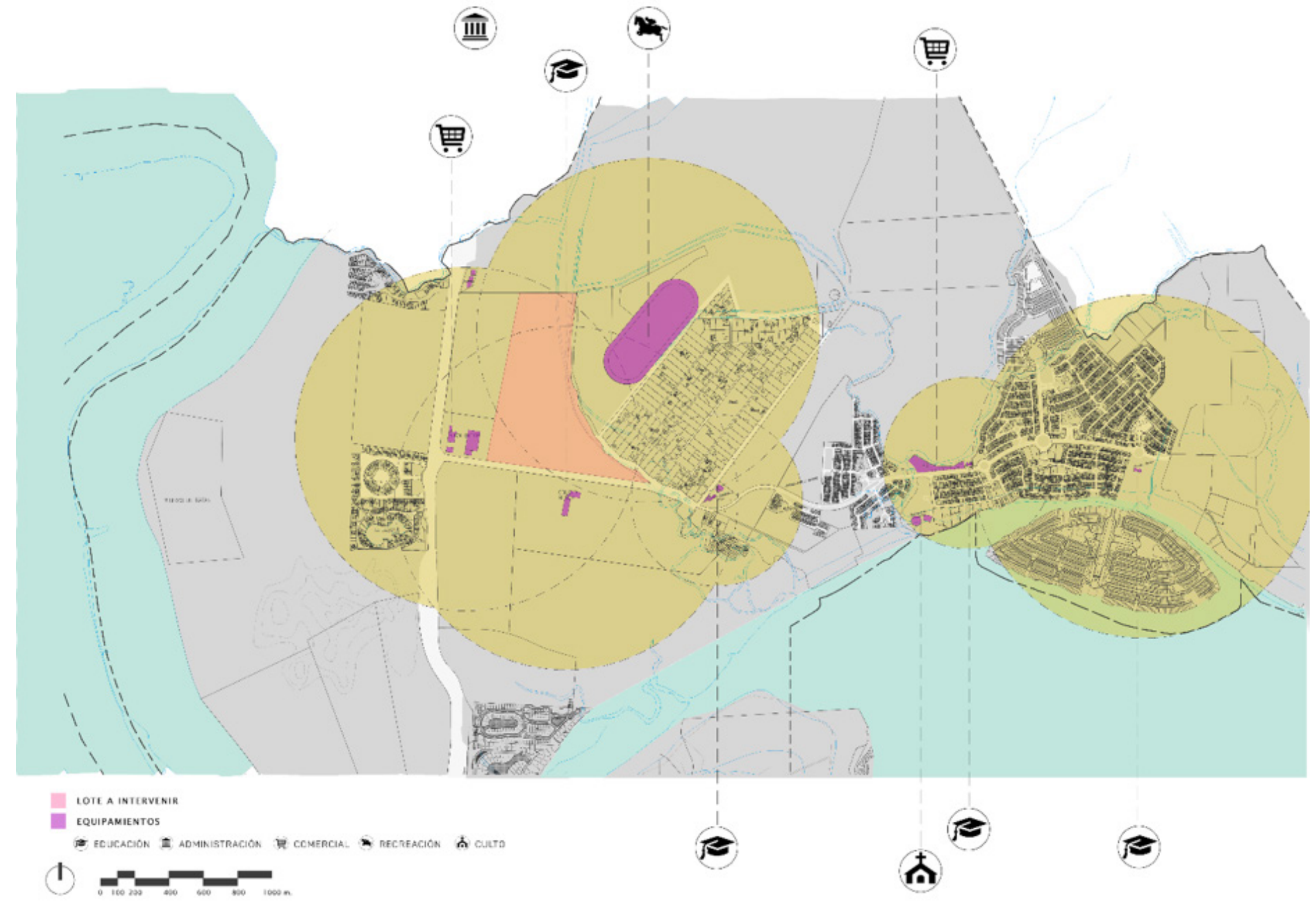


Es posible establecer que en la zona de intervención existe un predominio de los equipamientos de tipo educativo. Los radios de uso de estos abarcan casi en su totalidad la zona a la cual pertenecen, pero debido a la baja densidad poblacional existente en el área con alta disponibilidad de extensos terrenos naturales destinados a actividades agrícolas o privatizados para futuros proyectos inmobiliarios, los equipamientos educativos existentes satisfacen necesidades de pobladores que residen fuera de sus radios de acción o uso. En cuanto a los equipamientos administrativos y comerciales identificados en el sector, estos satisfacen las necesidades y demandas de sus habitantes dado su radio de uso a nivel de ciudad. Con respecto a los equipamientos de categoría recreación/cultura, a excepción de la iglesia localizada en el sector cuyo radio de uso abarca a la ciudad de Samborondón, el hipódromo identificado no es suficiente para satisfacer las necesidades y demandas recreacionales de ocio y esparcimiento de la población de la zona de estudio, presentándose entonces un déficit en equipamientos recreacionales y culturales.

\section{Vialidad y Movilidad Sustentable:}

En la zona de estudio durante los dos últimos años, se ha llevado a cabo por parte de la municipalidad un proyecto de regeneración y reestructuración urbana a lo largo de la Avenida León Febres Cordero, vía principal de ingreso de la zona de intervención. Esta iniciativa ha dotado al área urbana de nuevos y mejores espacios para la movilidad urbana por medio de ampliación de vías vehiculares y peatonales, a su vez de la dotación de ciclo vías, paradas de buses y franjas de vegetación a lo largo de las distintas vías existentes. De este modo, a lo largo de las vías urbanas que comprende la zona de intervención, existe un grado de accesibilidad óptimo para los peatones, ciclistas y

Figura 12. Vialidad y Servicio de Transporte Público.

Fuente: Elaboración propia (2018). usuarios de transporte público al poder contar con espacios nuevos y rediseñados para la integración de los mismos dentro del tejido urbano de la ciudad.

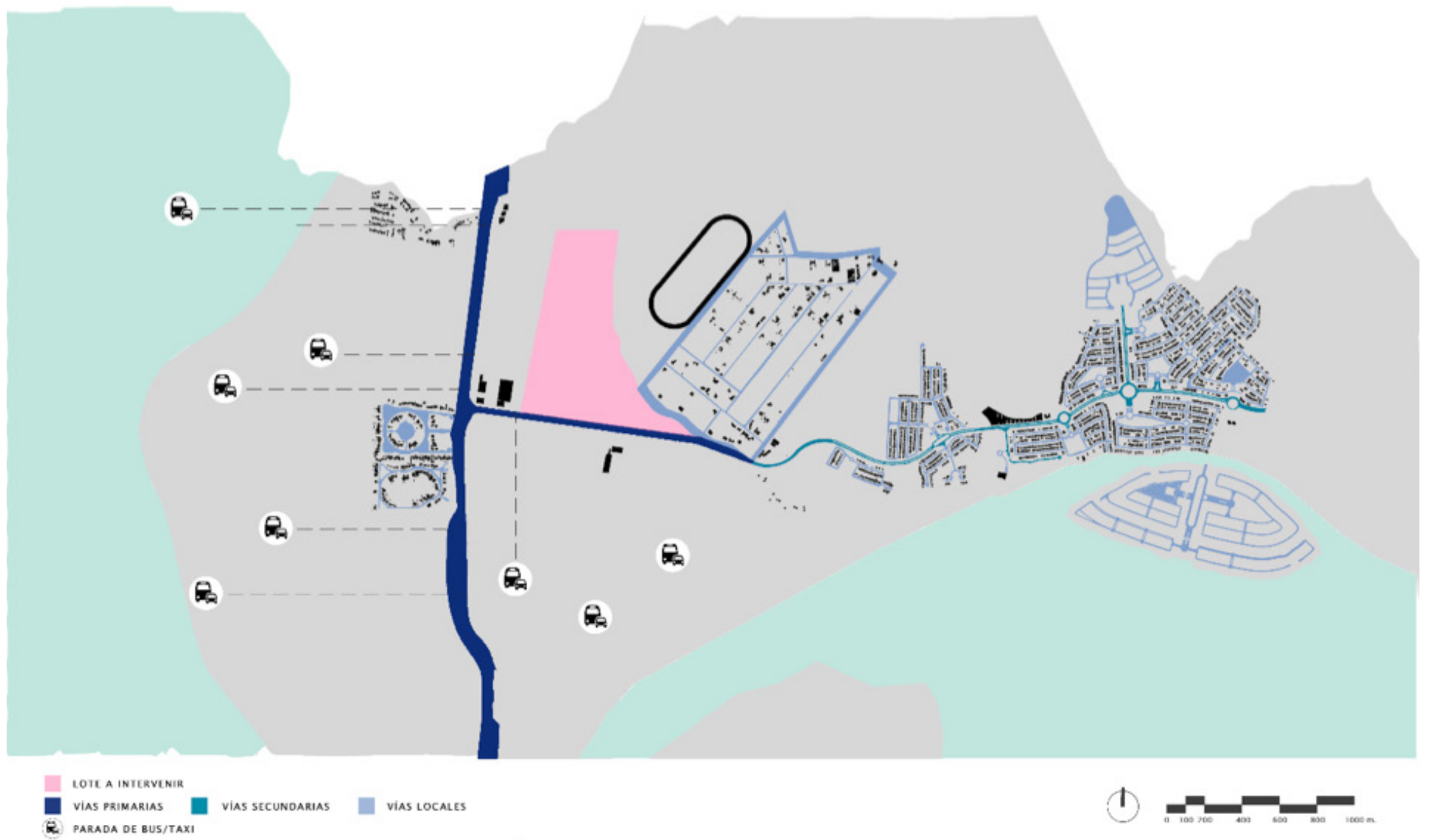

En vista de que el área de estudio se encuentra atravesando un desarrollo exponencial, manteniendo un eje de crecimiento horizontal al igual que el resto de la ciudad de Samborondón, la principal calle comercial que existe dentro de esta es la Av. León Febres Cordero, misma que deriva de la Vía Samborondón, la cual es otra calle comercial prioritaria, adentrándose hacia la urbanización Ciudad Celeste (ver figura 26). Considerando que la mencionada avenida es relativamente nueva, esta no 
presenta mayor conflicto entre peatones y autos. Sin embargo, al adentrarse a la zona de desarrollo de la urbanización Ciudad Celeste, se evidencian ciertas diferencias que desembocan en el decrecimiento de la eficiencia y calidad del sistema de movilidad urbana (ver Figura 12).

Figura 13. Diagramación de Esquema Funcional.

Fuente: Elaboración propia (2018)

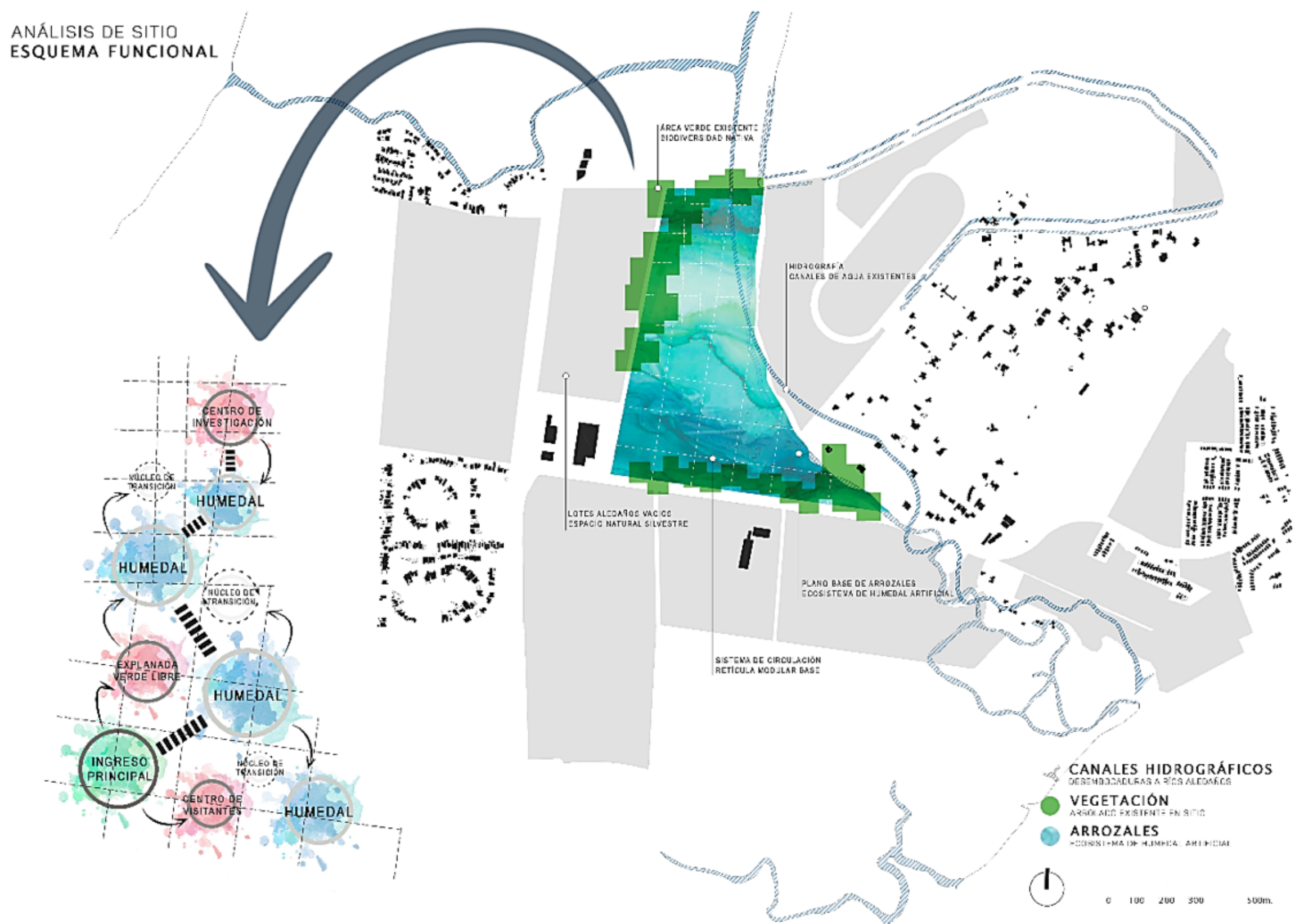

Mediante la realización del esquema funcional correspondiente a la zona de intervención, se evidencia la presencia de tres elementos que establecieron las directrices para la concepción y diseño de la propuesta de Jardín Botánico: canales hidrográficos, vegetación existente y arrozales. Dichos elementos se conjugan al dotar el terreno de un contexto firme sobre el cual se disponen y adaptan las áreas a funcionar dentro del proyecto, resolviendo de tal forma la ubicación del ingreso principal (Centro de Investigación y Centro de Visitantes), de las explanadas de área verde libre y los núcleos de transición de espacios. Esto logra un impacto mínimo en el funcionamiento de los arrozales existentes. 
Tabla 5. Programa de Necesidades Jardín Botánico.

Fuente: Elaboración propia (2018)

Tabla 6. Programa de Necesidades Centro de Visitantes.

Fuente: Elaboración propia (2018).

Tabla 7. Programa de Necesidades Centro de Investigador.

Fuente: Elaboración propia (2018).
Programa de Necesidades:

Tabla 5.

Programa de Necesidades Jardín Botánico

\begin{tabular}{|c|c|c|c|}
\hline ZONA & $\begin{array}{c}\text { ESPACIO } \\
\text { ARQUITECTÓNICO }\end{array}$ & $\begin{array}{c}\text { ÁREA TOTAL } \\
\text { (m2) }\end{array}$ & $\begin{array}{l}\text { PORCENTAJE DE } \\
\text { USO }\end{array}$ \\
\hline \multirow{4}{*}{ Recreación } & Centro de Visitantes & 3000 & \multirow{4}{*}{$0,01 \%$} \\
\hline & $\begin{array}{l}\text { Explanadas de área verde } \\
\text { libre }\end{array}$ & 2000 & \\
\hline & Área de Picnic & 2000 & \\
\hline & Área de Juegos infantiles & 2000 & \\
\hline \multirow{2}{*}{ Circulación } & Muelles y Plataformas & 16000 & \multirow{2}{*}{$10 \%$} \\
\hline & Senderos pavimentados & 34453,85 & \\
\hline Área verde & Áreas con vegetación & 126369,75 & $30 \%$ \\
\hline Área de cultivos & $\begin{array}{l}\text { Humedales artificiales } \\
\text { (arrozales) }\end{array}$ & 295335,4 & $60 \%$ \\
\hline \multirow{5}{*}{ Educación y cultura } & Centro de Investigación & 2000 & \multirow{5}{*}{$0,02 \%$} \\
\hline & Huertos orgánicos & 2000 & \\
\hline & Administración & 500 & \\
\hline & Baterías de Baños & 400 & \\
\hline & Instalaciones Eléctricas & 300 & \\
\hline \multirow[t]{4}{*}{ Servicios generales } & Instalaciones Sanitarias & 500 & \multirow[t]{4}{*}{$0,01 \%$} \\
\hline & Bodegas & 500 & \\
\hline & Guardianía & 200 & \\
\hline & Parqueo Público & 3000 & \\
\hline \multicolumn{2}{|c|}{ ÁREA TOTAL JARDÍN BOTÁNICO: } & 490559 & $100 \%$ \\
\hline
\end{tabular}

Tabla 6.

Programa de Necesidades Centro de Visitantes

\begin{tabular}{|c|c|c|c|c|}
\hline ZONA & $\begin{array}{c}\text { ESPACIO } \\
\text { ARQUITECTÓNICO }\end{array}$ & $\begin{array}{l}\text { ÁREA } \\
\text { (m2) }\end{array}$ & CANTIDAD & $\begin{array}{l}\text { ÁREA TOTAL } \\
\text { (m2) }\end{array}$ \\
\hline \multirow{7}{*}{$\begin{array}{c}\text { Gerencia y } \\
\text { Administración }\end{array}$} & Vestíbulo & 300 & 1 & 300 \\
\hline & Recepción & 20 & 1 & 20 \\
\hline & Oficinas Administrativas & 170 & 1 & 170 \\
\hline & Zonas de Exhibición & 500 & 1 & 500 \\
\hline & Biblioteca & 300 & 1 & 300 \\
\hline & Salas de Uso Múltiple & 90 & 4 & 360 \\
\hline & Salas de Conferencias & 100 & 2 & 200 \\
\hline \multirow[t]{9}{*}{ Zona Pública } & Auditorio & 400 & 1 & 400 \\
\hline & Cafetería & 200 & 1 & 200 \\
\hline & Tienda de Souvenirs & 20 & 1 & 20 \\
\hline & Zona de Coworking & 12 & 4 & 48 \\
\hline & Jardines Interiores & 20 & 3 & 60 \\
\hline & Batería de baños & 100 & 2 & 200 \\
\hline & Bodegas & 15 & 4 & 60 \\
\hline & Utilería y Limpieza & 6 & 3 & 18 \\
\hline & Cuartos de Climatización & 2 & 20 & 40 \\
\hline \multirow[t]{5}{*}{ Servicios Generales } & Paneles Eléctricos & 2 & 2 & 4 \\
\hline & Cuarto de Bombas & 20 & 1 & 20 \\
\hline & Cuarto de Basura & 10 & 1 & 10 \\
\hline & $\begin{array}{l}\text { Área de Carga y } \\
\text { Descarga }\end{array}$ & 70 & 1 & 70 \\
\hline & \multicolumn{3}{|c|}{ ÁREA TOTAL CENTRO DE VISITANTES: } & 3000 \\
\hline
\end{tabular}

Tabla 7.

Programa de Necesidades Centro de Investigación

\begin{tabular}{|c|c|c|c|c|}
\hline ZONA & $\begin{array}{c}\text { ESPACIO } \\
\text { ARQUITECTÓNICO }\end{array}$ & $\begin{array}{l}\text { ÁREA } \\
\text { (m2) }\end{array}$ & CANTIDAD & $\begin{array}{l}\text { ÁREA TOTAL } \\
(\mathrm{m} 2)\end{array}$ \\
\hline \multirow{6}{*}{$\begin{array}{c}\text { Dirección y } \\
\text { Administración }\end{array}$} & Vestibulo & 200 & 1 & 200 \\
\hline & Recepción & 30 & 1 & 30 \\
\hline & Oficina Dirección & 20 & 2 & 40 \\
\hline & $\begin{array}{l}\text { Cubiculos de } \\
\text { Investigadores }\end{array}$ & 10 & 10 & 100 \\
\hline & Sala de Reuniones & 20 & 2 & 40 \\
\hline & Laboratorio de Ecología & 100 & 1 & 100 \\
\hline \multirow{5}{*}{$\begin{array}{c}\text { Zona de } \\
\text { Investigación }\end{array}$} & $\begin{array}{l}\text { Laboratorio de } \\
\text { Sedimentologia }\end{array}$ & 100 & 1 & 100 \\
\hline & Laboratorio de Hidrografia & 100 & 1 & 100 \\
\hline & Laboratorio de Botánica & 100 & 1 & 100 \\
\hline & Laboratorio de Geologia & 100 & 1 & 100 \\
\hline & Biblioteca & 100 & 1 & 100 \\
\hline \multirow{4}{*}{ Zona Pública } & Sala de uso múltiple & 90 & 3 & 270 \\
\hline & Cafeteria & 160 & 1 & 160 \\
\hline & Zona de Coworking & 200 & 1 & 200 \\
\hline & Jardines Interiores & 20 & 4 & 80 \\
\hline \multirow{8}{*}{ Servicios Generales } & Batería de baños & 100 & 1 & 100 \\
\hline & Bodegas & 12 & 5 & 60 \\
\hline & Utileria y Limpieza & 6 & 3 & 18 \\
\hline & Cuartos de Climatización & 2 & 10 & 20 \\
\hline & Paneles Eléctricos & 2 & 1 & 2 \\
\hline & Cuarto de Bombas & 20 & 1 & 20 \\
\hline & Área de Carga y Descarga & 60 & 1 & 60 \\
\hline & \multicolumn{3}{|c|}{ ÁREA TOTAL CENTRO DE INVESTIGACIÓN: } & 2000 \\
\hline
\end{tabular}


Figura 14. Diagrama de Concepto. Fuente: Elaboración propia (2018).

Figura 15. Diagrama de Criterios de Diseño. Fuente: Elaboración propia (2018).
ARTíCULO | Diana Belén Gutiérrez Vallejo, Mª Daniela Hidalgo Molina | Conservación de Humedales mediante un jardín botánico como espacio transitorio entre lo urbano y rural

\section{Concepto y criterios de diseño:}

El concepto del cual parte la propuesta de diseño se concibe a través de una figuración formal del ecotono, mismo que al significar transición se representa gráficamente mediante un trazado horizontal sinuoso. Este se presenta como una constante en la transición de espacios en ecosistemas naturales. Dicho trazado, compuesto por una serie de curvas, es luego superpuesto entre sí, dando como resultado una serie de módulos, los cuales generan una nueva composición formal analógica: la figuración de la espiga del arroz. Mediante la abstracción geométrica de la analogía formal, la regularización de la forma conlleva a la concepción de un nuevo módulo, mismo que al disponerse en torno a dos ejes de simetría genera finalmente una composición geométrica que destaca la concepción formal clave para el trazado de la implantación del proyecto: un sistema ramificado de senderos con núcleos de encuentro (Ver Figuras 14 y 15).

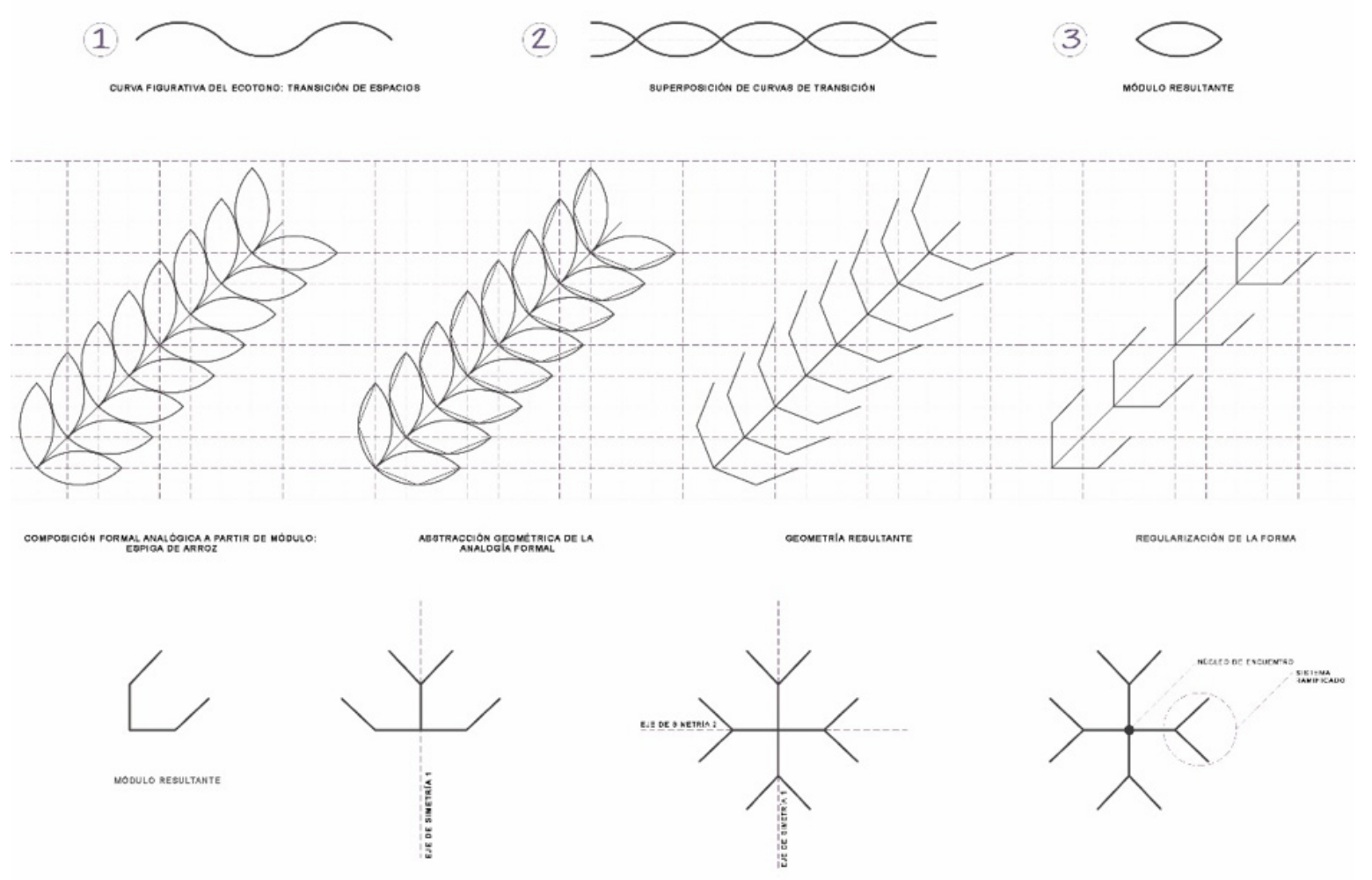

ZRITERIOS DE DISEÑO
ZCOTNO ESPACIOS DE TRANSICION
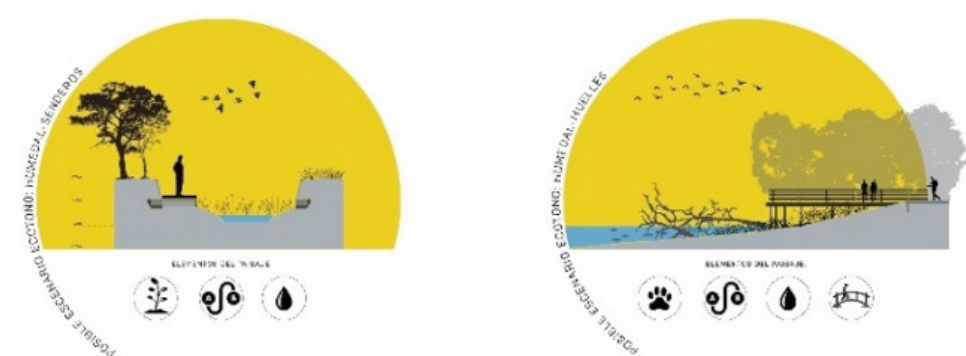

(4) of 10
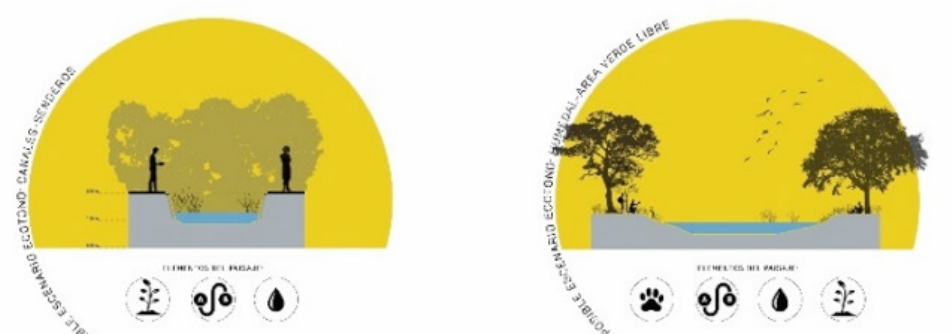
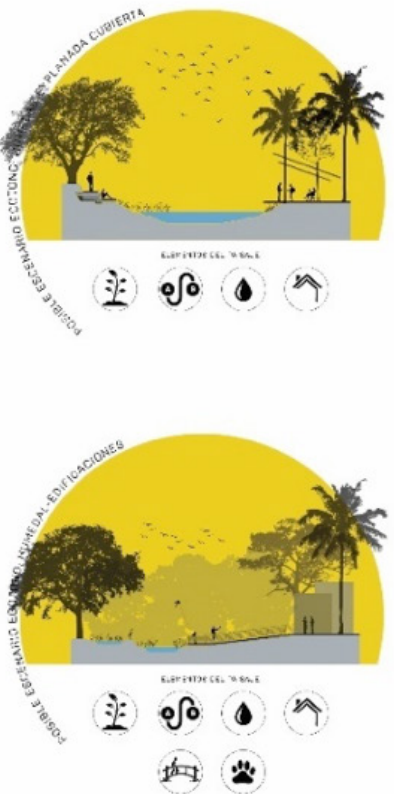

ESTRATEGIA tuteer 
Figura 16. Diagrama de Criterios de Diseño. Fuente: Elaboración propia (2018).
Figura 17. Master Plan del Proyecto. Fuente: Elaboración propia (2018).

\section{Diagramas de Formación:}
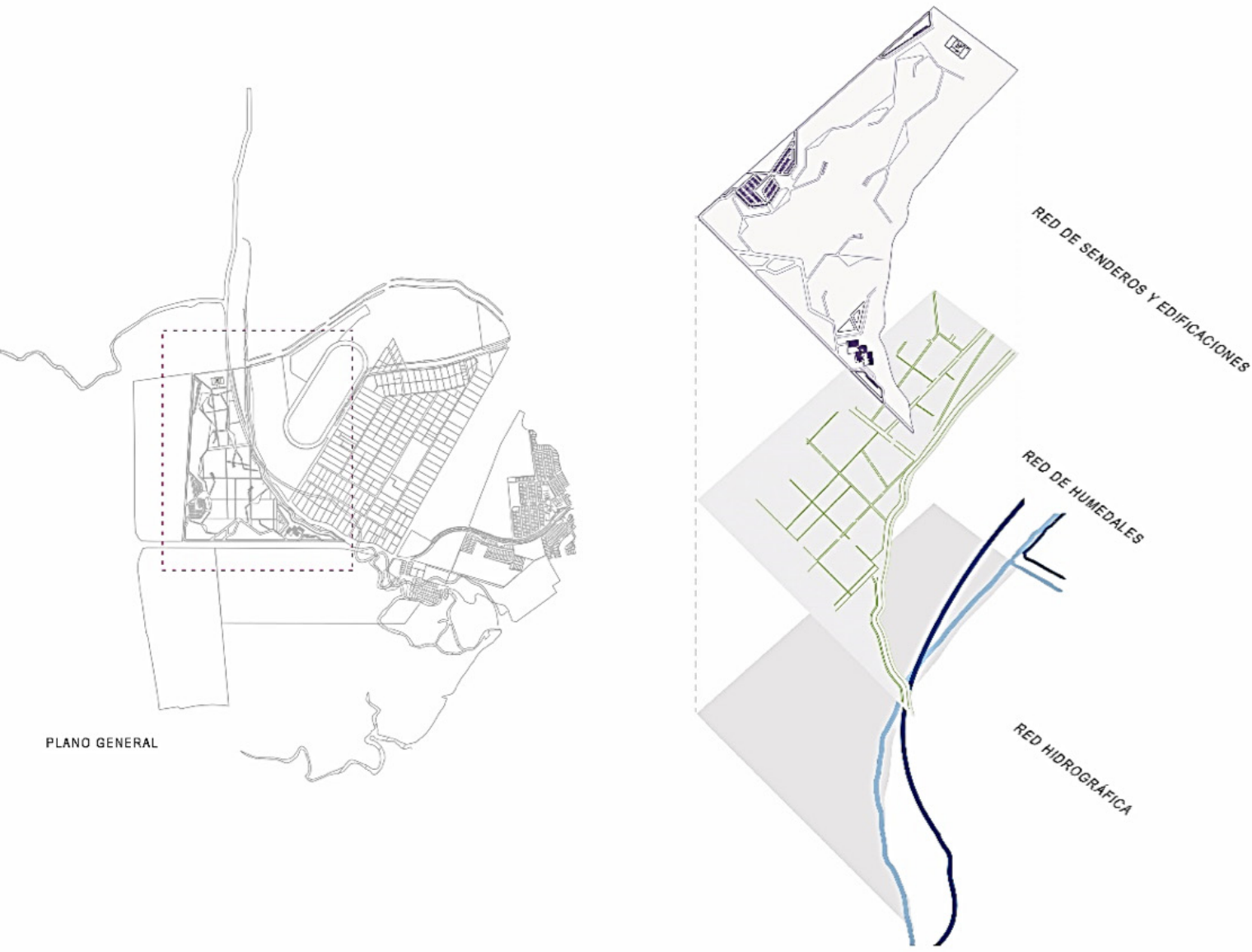

El proyecto da cabida a tres redes principales: red hidrográfica, red de humedales, y red de senderos y edificaciones. La red hidrográfica figura como aquel elemento intangible dentro del sitio de estudio que actúa como condicionante dentro del proyecto. La red de humedales consiste en un sistema de caminos de tierra dispuestos en función de las zonas de cultivo de arroz existentes a manera de retícula dentro del terreno. A diferencia de la red hidrográfica, la red de humedales si presentará intervenciones en su composición previa con el fin de albergar nuevos espacios arquitectónicos y escenarios naturales, determinados por el diseño de la red de senderos y edificaciones (Ver Figura 16).

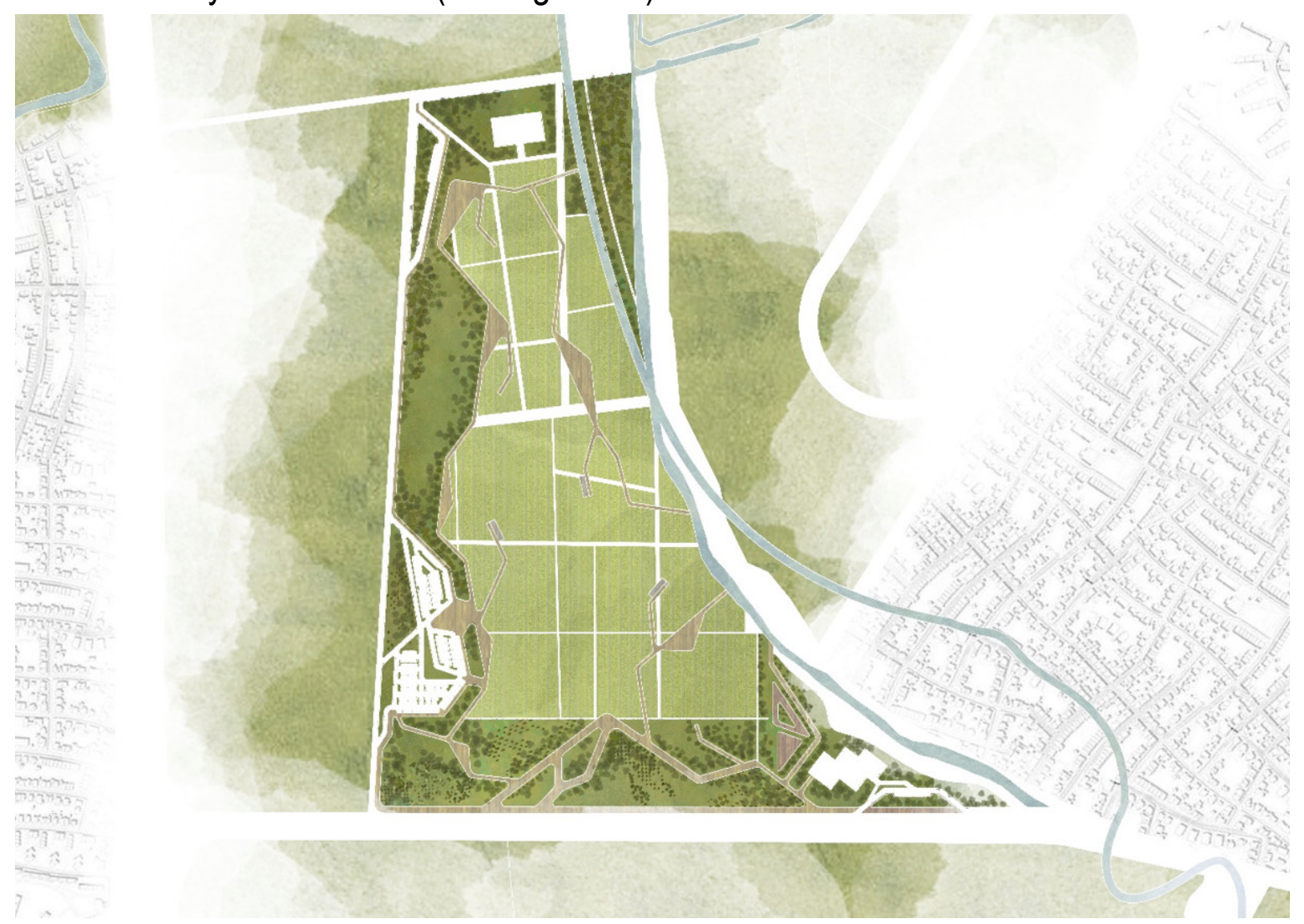

Planimetría y Renders:

1. Humedales.

2. Centro de Visitantes.

3. Centro de Investigación.

4. Parqueos. 
Figura 18. Planta Arquitectónica Centro de Vigilantes.

Fuente: Elaboración propia (2018).

Figura 19. Fachada Frontal Centro de Visitantes.

Fuente: Elaboración propia (2018).

Figura 20. Fachada Lateral Centro de Visitantes. Fuente: Elaboración propia (2018).

Figura 21. Sección AA Centro de Visitantes. Fuente: Elaboración propia (2018).
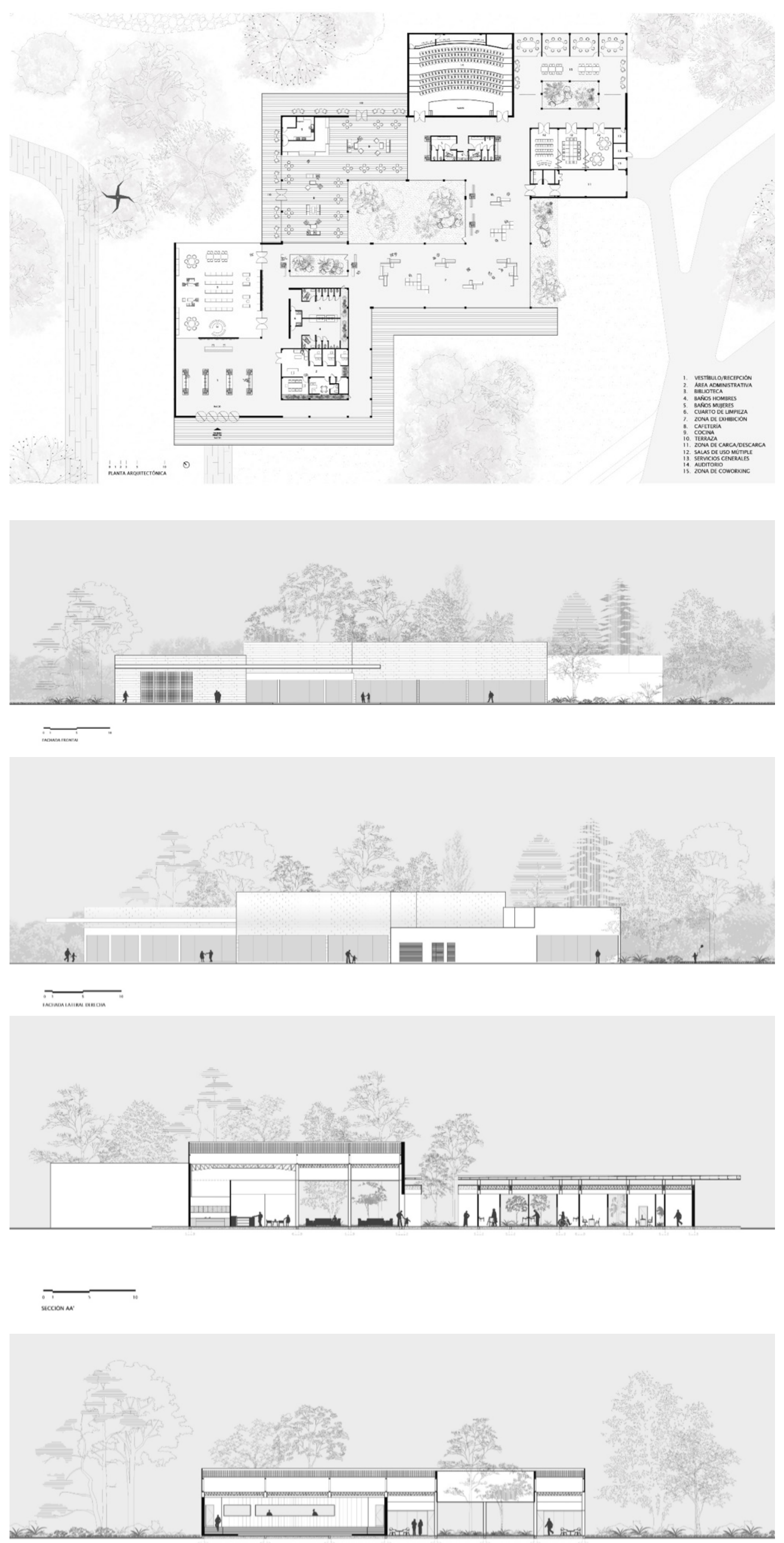
Figura 23. Planta Arquitectónica Baja Centro de Investigación.

Fuente: Elaboración propia (2018).

Figura 24. Planta Arquitectónica Alta Centro de Investigación

Fuente: Elaboración propia (2018).

Figura 25. Fachada Frontal Centro de Investigación.

Fuente: Elaboración propia (2018).

Figura 26. Fachada Posterior Centro de Investigación.

Fuente: Elaboración propia (2018).

Figura 27. Sección AA Centro de Investigación. Fuente: Elaboración propia (2018).
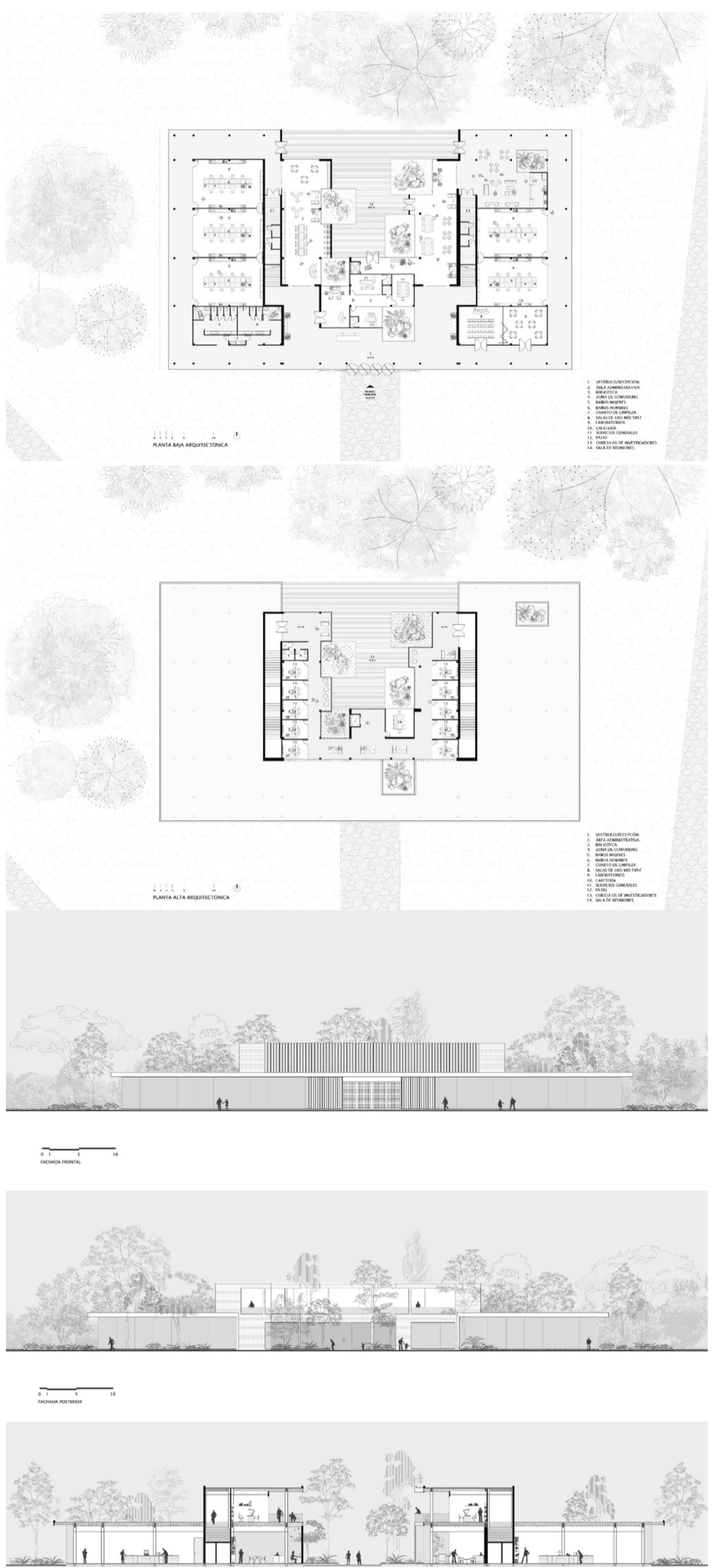

$\overline{126}$ 
Figura 28. Sección BB Centro de Investigación. Fuente: Elaboración propia (2018).

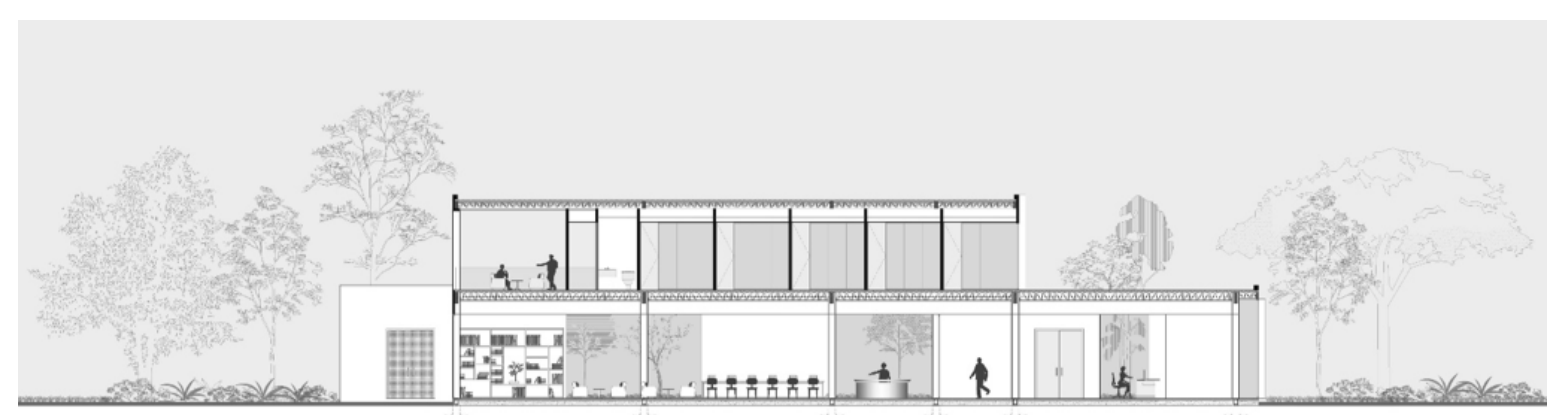

Figura 29. Perspectiva Exterior Centro de Visitantes.

Fuente: Elaboración propia (2018).

Figura 30. Perspectiva Interior Centro de Visitantes.

Fuente: Elaboración propia (2018).

Figura 31. Perspectiva Exterior Centro de Investigación.

Fuente: Elaboración propia (2018).

Figura 32. Perspectiva Exterior Centro de Investigación.

Fuente: Elaboración propia (2018)

SECCOÓN BB:
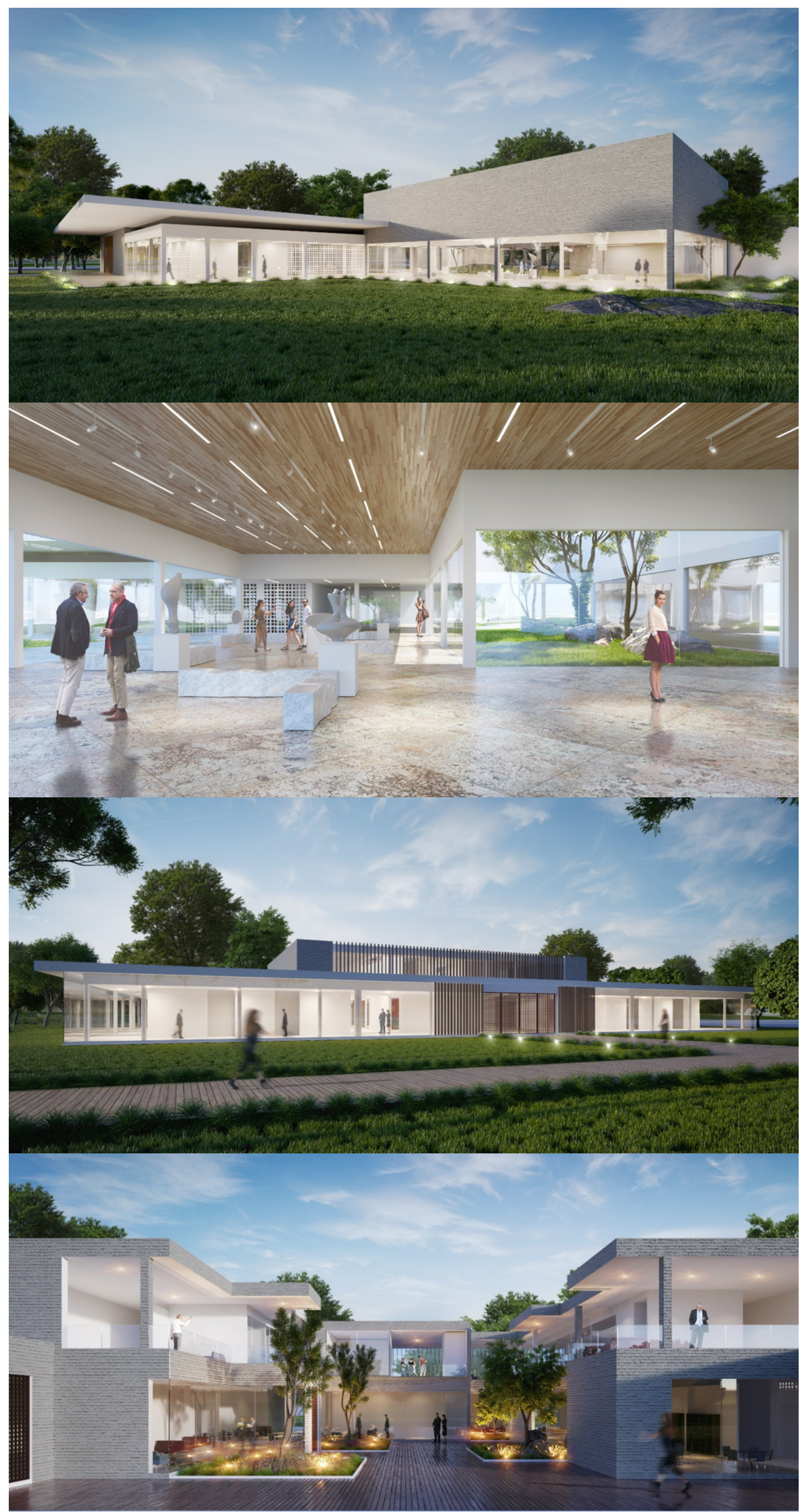
Figura 33. Perspectiva Interior Centro de Investigación.

Fuente: Elaboración propia (2018).

Figura 34. Perspectiva de paisaje del Jardín Botánico.

Fuente: Elaboración propia (2018).

Figura 35. Perspectiva de paisaje del Jardín Botánico.

Fuente: Elaboración propia (2018).

Figura 36. Perspectiva de paisaje del Jardín Botánico.

Fuente: Elaboración propia (2018).
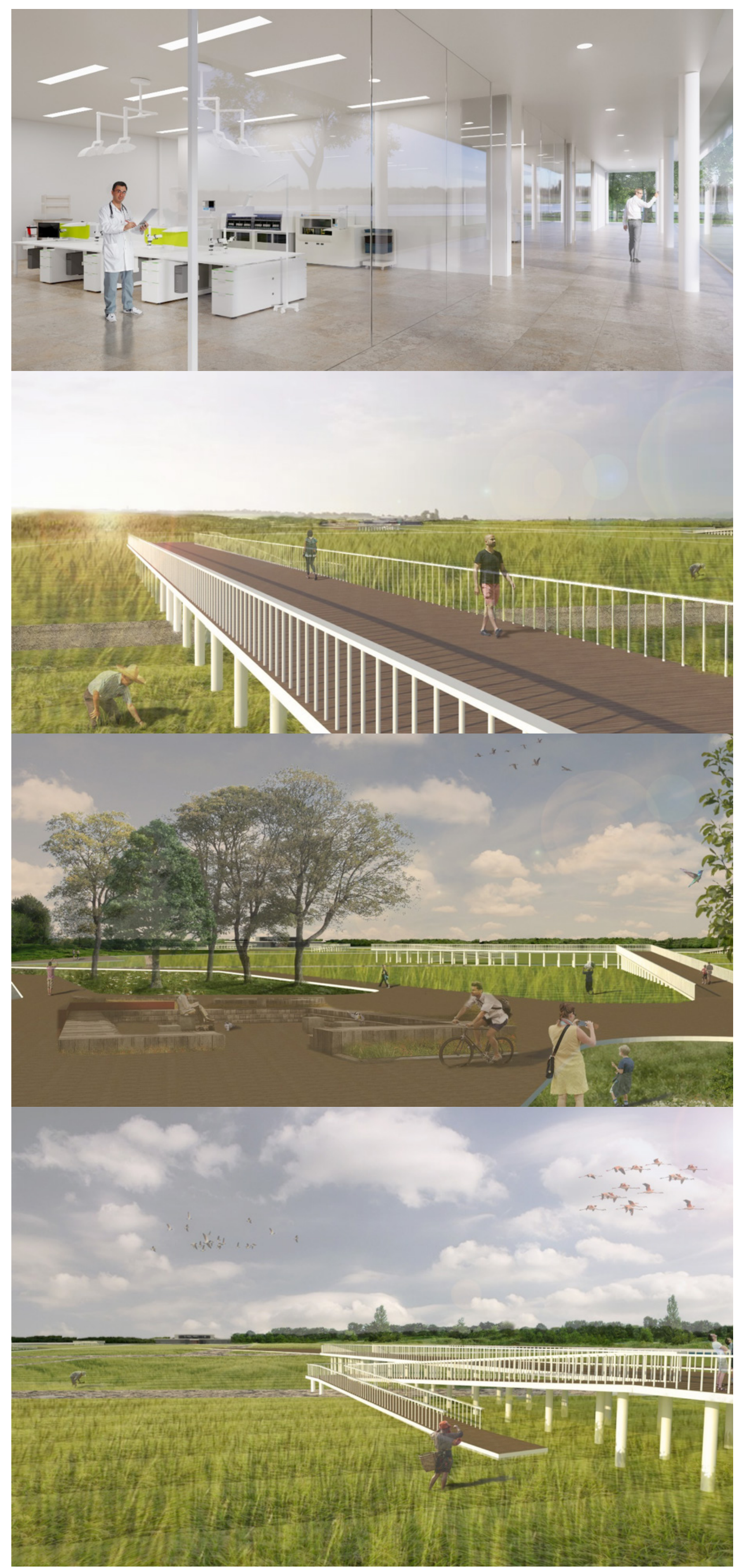


\section{Conclusiones}

El cantón de Samborondón, siendo una ciudad emergente, ha experimentado cambios desde los años setenta, sobre todo en la parroquia La Puntilla que pasó de ser una parroquia rural agrícola arrocera a una parroquia urbana con alto crecimiento poblacional, económico y urbano. Por tanto, es necesario una planificación urbana estratégica responsable que prometa, sobre todo, un futuro sostenible para su comunidad. Innumerables son los proyectos inmobiliarios desarrollados y por desarrollar dentro de esta zona, siendo estos en su mayoría proyectos de tipo residencial y comercial. Sin embargo, es notable la deficiencia de espacios públicos dispuestos para el uso y disfrute de su población. En vista de la inexistencia de un espacio público dentro del territorio urbano y de la invaluable biodiversidad presente en el cantón, en el presente trabajo se ha propuesto un modelo de jardín botánico para la conservación del ecosistema de humedales arroceros de la parroquia urbana La Puntilla que contempla espacios tanto arquitectónicos como naturales acoplados a las diversas necesidades sociales y medio ambientales identificadas. Además, se convierte el espacio de transición entre lo urbano y rural. Es así como la propuesta urbana-arquitectónica cuenta con puntos estratégicos de contemplación, espacios recreativos activos y pasivos, senderos, explanadas de área verde libre, centro de visitantes y centro de investigación, lo cual converge dentro de un ecosistema que enfrentará un impacto mínimo al conservar al máximo sus tesoros naturales y función original como arrozal, alcanzando aquella sinergia deseada entre naturaleza, arquitectura y comunidad.

\section{Recomendaciones}

La alianza estratégica con instituciones nacionales e internacionales involucradas con el manejo y desarrollo de tecnologías, medio ambiente y educación determinará el adecuado uso, crecimiento y evolución del proyecto planteado.

La realización constante de actividades de índole turística y cultural dentro de los espacios arquitectónicos propuestos en el jardín botánico resultan de vital importancia para cubrir gastos de mantenimiento que demandará el proyecto, el cual se destinaría en su totalidad al uso público y libre por parte de la comunidad de Samborondón.

Un estudio de impacto ambiental en conjunto con demás ingenierías relevantes al proyecto permitirá cumplir a totalidad la misión de conservación del ecosistema de humedales de la presente propuesta urbana-arquitectónica.

\section{Referencias bibliográficas}

Naciones Unidas. (2015). Objetivo 11 del Desarrollo Sostenible. Agenda Urbana 2030. Recuperado de https://www.un.org/sustainabledevelopment/es/cities/

Alcaldía de Samborondón. (2018). Historia de Samborondón. Recuperado de http:// www.samborondon.gob.ec/samborondon/historia/

Alfonso Olaya, J., \& Riascos Romo, E. (2016). El Ecotono Urbano como estrategia integral de conectividades. Bogotá.

ARCGIS. (2018). [llustración gráfica de ARCGIS Mayo, 2018] Mapa Satelital de Samborondón. Recuperado de https://www.arcgis.com/home/webmap/viewer. $\mathrm{html}$ ?useExisting=1

Ávila, H. (2009). Periurbanización y espacios rurales en la periferia de las ciudades. Estudios Agrarios, 93-123.

Bazant, J. (1983). Equipamiento. En J. B. S, Manual de Citerios de Diseño Urbano. México D.F.: Editorial Trillas.

Cuesta, A. (2012). Ecotono Urbano: Introducción conceptual para la alternatividad al desarrollo urbano. Bogotá: Universidad de La Salle. 
Estenssoro, F. (2014). El ecodesarrollo como concepto precursor del desarrollo sustentable y su influencia en América Latina. Recuperado de https://scielo. conicyt.cl/scielo.php?pid=S0718-23762015000100006\&script=sci_arttext

Gobernación del Guayas. (2018). Cantón Samborondón. Efemérides. Recuperado de http://www.efemerides.ec/1/nov/can_23.htm

Gobierno Autónomo Descentralizado de la Municipalidad de Samborondón. (2015). Plan Cantonal de Desarrollo y Plan de Ordenamiento Territorial (2015-2019).

Gobierno Autónomo Descentralizado Municipal del Cantón Samborondón. (2012). Sistema Ambiental. En G. A. Plan Cantonal de Desarrollo y Plan de Ordenamiento Territorial (2012-2022).

Gómez, C. (2014). El desarrollo Sostenible: Conceptos básicos, alcance y criterios para su evaluación. Recuperado de: http://www.unesco.org/new/fileadmin/ MULTIMEDIA/FIELD/Havana/pdf/Cap3.pdf

Hernández, S. (2008). Introducción al Urbanismo Sustentable o Nuevo Urbanismo. Revista Espacios Públicos, 298-307.

INEC. (2010). Proyección de la Población Ecuatoriana, por años calendario, según cantones 2010-2022. Recuperado de http://www.ecuadorencifras.gob.ec/ proyecciones-poblacionales/

Kayser, B. (1972). El espacio rural y el nuevo sistema de relaciones ciudad-campo. El espacio rural y el nuevo sistema de relaciones ciudad-campo. Barcelona: Equipo Urbano.

López, A. (2014). El papel de los "Ecotonos Urbanos" en la planificación de los corredores ecológicos de Ronda. Recuperado de https://repository.javeriana.edu. co/handle/10554/13989

López, I. (2015). Sobre el desarrollo sostenible y la sostenibilidad: Conceptualización y crítica. Revista Castellano-Manchega de Ciencias Sociales, 111-128.

Neu, T. (2016). El paisaje intermedio: entre lo urbano y lo rural. Una franja de transición. Opera, 55-81.

Secretaría Nacional de Planificación y Desarrollo. (2015). Agenda Zonal: Zona 8 Guayaquil, Samborondón y Durán. Quito: Senplades.

SENPLADES. (2013). Secretaría Nacional de Planificación y Desarrollo. Recuperado de http://www.planificacion.gob.ec/bibliotecal

Supraquam. (2015). Plan Cantonal de Desarrollo y Plan de Ordenamiento Territorial 2015-2019. En G. A. Plan Cantonal de Desarrollo y Plan de Ordenamiento Territorial 2015-2019.

Torres, E. (2013). La ley general del poder de Manuel Castells (1976-2009). Estudios Sociológicos, 691-719. 